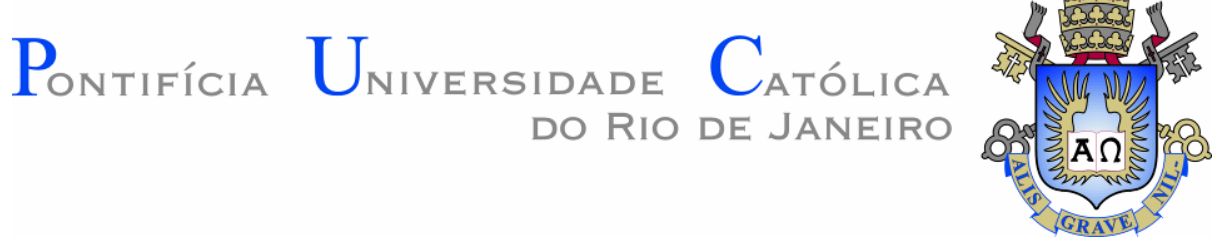

Higor França Minguita

Otimização do método QuEChERS em mexilhão para determinação de hidrocarbonetos policíclicos aromáticos (HPAs)

Dissertação de Mestrado

Dissertação apresentada ao programa de Pós-graduação em Química da PUC-Rio como requisito parcial para obtenção do grau de Mestre em Química pelo Programa de Pós-graduação em Química, do Departamento de Química da PUC-Rio.

Orientador: Prof. Renato da Silva Carreira 


\section{Otimização do método QuEChERS em mexilhão para determinação de hidrocarbonetos policíclicos aromáticos}

(HPAs)

Dissertação apresentada como requisito parcial para obtenção do grau de Mestre pelo Programa de Pósgraduação em Química do Departamento de Química da PUC-Rio. Aprovada pela Comissão Examinadora abaixo.

Prof. Renato da Silva Carreira

Orientador

Departamento de Química - PUC-Rio

Prof. Rivelino Martins Cavalcante

Universidade Federal do Ceará

Profa. Cláudia Hamacher

Universidade do Estado do Rio de Janeiro

Prof. Carlos German Massone

Departamento de Química - PUC-Rio

Rio de Janeiro, 18 de agosto de 2021 
Todos os direitos reservados. A reprodução, total ou parcial, do trabalho é proibida sem autorização da universidade, da autora e do orientador

Higor França Minguita

Graduou-se em Engenharia Química na Universidade Federal Fluminense em 2017. É pesquisador no Laboratório de estudos Marinhos e Ambientais (LABMAM) da PUC-Rio. Atua, principalmente, na otimização de métodos analíticos para determinar hidrocarbonetos policíclicos aromáticos em biota marinha.

Ficha Catalográfica

Minguita, Higor França

Otimização do método QuEChERS em mexilhão para determinação de hidrocarbonetos policíclicos aromáticos (HPAs) / Higor França Minguita; orientador: Renato da Silva Carreira. - 2021. 66 f.: il.; $30 \mathrm{~cm}$

Dissertação (mestrado)-Pontifícia Universidade Católica do Rio de Janeiro, Departamento de Química, 2021. Inclui bibliografia

1. Química - Teses. 2. HPAs. 3. Otimização. 4. Biota marinha. 5. QuEChERS. 6. GC-MS. I. Carreira, Renato da Silva. II. Pontifícia Universidade Católica do Rio de Janeiro. Departamento de Química. III. Título. 


\section{Agradecimentos}

Primeiramente agradeço a Deus, por me proteger, orientar e me dar força nos momentos difíceis que passei.

Agradeço à minha família, em especial a minha mãe que faz de tudo por mim, que sempre me colocou como prioridade em sua vida, a ela sou muito grato e tenho muito orgulho de ser seu filho.

Aos meus amigos que a UFF me deu e que continuam fazendo a diferença em minha vida, Cecília e Phelipe em especial, pois foram os que me deram motivação para embarcar nessa jornada acadêmica.

Agradeço ao Jefferson, por não desistir de mim, por me motivar diariamente, por acreditar que sou capaz e estar sempre ao meu lado quando mais preciso. Ele é o motivo pelo qual eu sou feliz hoje.

Ao meu orientador Renato Carreira, pela oportunidade de trabalhar nesse projeto e por todos os ensinamentos passados.

Agradeço ao LABMAM e sua equipe, em especial ao Otoniel, que foi meu braço direito nessa missão, com ele aprendi muitas coisas e agradeço cada minuto do seu tempo em tirar minhas dúvidas e me escutar.

Agradeço à PUC-Rio, ao Departamento de Química, ao Programa de Pósgraduação em Química e a CAPES, por proporcionar a estrutura necessária para a realização deste trabalho.

O presente trabalho foi realizado com apoio da Coordenação de Aperfeiçoamento de Pessoal de Nível Superior - Brasil (CAPES) - Código de Financiamento 001. 


\section{Resumo}

Minguita, Higor França; Carreira, Renato da Silva. Otimização do método QuEChERS em mexilhão a para determinação de hidrocarbonetos policíclicos aromáticos (HPAs). Rio de Janeiro, 2021. 66p. Dissertação de Mestrado - Departamento de Química, Pontifícia Universidade Católica do Rio de Janeiro.

Os hidrocarbonetos policíclicos aromáticos (HPAs) de origem antrópica representam uma classe de contaminantes de relevância ambiental por serem derivados de múltiplas fontes petrogénicas e/ou pirolíticas e por apresentarem efeitos tóxicos e carcinogênicos. Quando encontrados em pescados de consumo comercial, podem apresentar um risco adicional para a saúde humana. A análise de HPAs em biota é um desafio analítico, devido à complexidade da matriz e aos níveis baixos de concentração que representam risco para o consumo de pescados. Esse trabalho tem como objetivo otimizar e validar o método QuEChERS para análise de HPAs em tecidos biológicos como uma alternativa aos métodos convencionais. O método QuEChERS apresenta características importantes para a Química Verde, ou seja, reduz o consumo excessivo de solventes, reagentes, quantidade de amostra, tempo, entre outros fatores que diminuem o impacto ambiental. Os parâmetros que afetam a eficiência do método foram estudados e concluiu-se que a etapa de purificação constituída por $Z_{-}$sep $^{+}$com uma coluna fina de sílica e alumina apresentou melhores condições de purificação do extrato. A determinação dos compostos por cromatografia a gás acoplada à espectrometria de massas (GC-MS) nos forneceu resultados com alta resolução, seletividade e detectibilidade. A linearidade e sensibilidade do método apresentou valores maiores que 0,990 para todos os HPAs, numa faixa de concentração de $1 \mathrm{ng} \mathrm{mL}^{-1}$ a $50 \mathrm{ng} \mathrm{mL}^{-1}$ no extrato final; limites de detecção e quantificação nos intervalos de 0,377 a 7,45 $\mathrm{ng} \mathrm{g}^{-1} \mathrm{e}$ 1,13 a 22,36 $\mathrm{ng} \mathrm{g}^{-1}$. Os percentuais de recuperação do método ficaram na faixa de 70 a $130 \%$. O procedimento validado permite quantificar HPAs em biota marinha de forma rápida, a baixo custo, livre de interferentes na análise instrumental por GC-MS e em níveis de quantificação que permitem avaliar a qualidade de pescados para consumo humano segundo padrões internacionais.

\section{Palavras-chave}

HPAs; Otimização; biota marinha; QuEChERS; GC-MS. 


\section{Abstract}

Minguita, Higor França; Carreira, Renato da Silva. Optimization of QuEChERS method in mussel for the determination of polycyclic aromatic hydrocarbons (PAHs). Rio de Janeiro, 2021. 66p. Dissertação de Mestrado - Departamento de Química, Pontifícia Universidade Católica do Rio de Janeiro.

Polycyclic aromatic hydrocarbons (PAHs) of anthropogenic origin represent a class of contaminants of environmental relevance because they are derived from multiple petrogenic and/or pyrolytic sources and because they have toxic and carcinogenic effects. When found in commercially relevant fish, they can pose an additional risk to human health. The analysis of HPAs in biota is an analytical challenge, due to the complexity of the matrix and the low levels of concentration that pose a risk to fish consumption. This work aims to optimize and validate the QuEChERS method for analysis of PAHs in biological tissues as an alternative to conventional. The QuEChERS method presenting important characteristics for Green Chemistry, that is, reducing the excessive consumption of solvents, reagents, sample quantity, time, among other factors that reduce the environmental impact. The parameters that affect the efficiency of the method were studied and it was concluded that the purification step consisting of Z-sep ${ }^{+}$with a thin column of silica and alumina presented better conditions for extract purification. The determination of compounds by gas chromatography coupled with mass spectrometry (GC-MS) provided us with results with high resolution, selectivity and detectability. The linearity and sensitivity of the method presented values greater than 0.990 for all PAHs, in a concentration range from $1 \mathrm{ng} \mathrm{mL}^{-1}$ to $50 \mathrm{ng} \mathrm{mL}^{-1}$ in the final extract; limits of detection and quantification in the ranges of 0.377 to $7.45 \mathrm{ng} \mathrm{g}^{-1}$ and 1.13 to $22.36 \mathrm{ng} \mathrm{g}^{-1}$. The method's recovery percentages ranged from 70 to $130 \%$. The validated procedure allows quantifying PAHs in marine biota quickly, at low cost, free from interferences in the instrumental analysis by GC-MS and at quantification levels that allow the quality of fish for human consumption to be assessed according to international standards.

\section{Keywords}

PAHs; Optimization; Marine biota; QuEChERS; GC-MS. 


\section{Sumário}

$\begin{array}{ll}\text { 1. Introdução } & 13\end{array}$

$\begin{array}{ll}\text { 1.1. Objetivo } & 15\end{array}$

1.2. Objetivos Específicos 15

2. Revisão Bibliográfica 16

$\begin{array}{ll}\text { 2.1. Mexilhão } & 16\end{array}$

2.2. Hidrocarbonetos policíclicos aromáticos (HPAs) 17

$\begin{array}{ll}\text { 2.3. Fontes } & 18\end{array}$

$\begin{array}{ll}\text { 2.4. Propriedades físico-químicas } & 20\end{array}$

2.5. Determinação de HPAs 21

2.6. Métodos analíticos para extração de HPAs 22

2.6.1. Extração por Soxhlet 22

2.6.2. Extração assistida por micro-ondas 24

2.6.3. Extração líquido pressurizada 25

2.6.4. Extração por QuEChERS 26

2.7. Técnicas cromatográficas para determinar HPAs 29

2.7.1. Cromatografia a líquido de alta eficiência (HPLC) 29

2.7.2. Cromatografia em fase gasosa (GC) - Espectrometria de
massas (MS)

2.8. Validação do método analítico 32

2.8.1. Linearidade 33

2.8.2. Sensibilidade 33

$\begin{array}{ll}\text { 2.8.3. Seletividade } & 33\end{array}$ 
2.8.4. Limite de detecção (LD) e Limite de Quantificação (LQ)

\section{Materiais e Métodos}

3.1. Procedimento Experimental

3.1.1. Amostras 35

3.1.2. Higienização dos materiais 35

3.1.3. Descarte dos resíduos 35

3.1.4. Padrões analíticos 36

3.1.5. Solventes, adsorventes e sais 36

3.1.6. Equipamentos 36

3.1.7. Parâmetros Cromatográficos 36

$\begin{array}{ll}\text { 3.2. Ensaios de Validação } & 37\end{array}$

$\begin{array}{ll}\text { 3.2.1. Linearidade } & 37\end{array}$

$\begin{array}{ll}\text { 3.2.2. Sensibilidade } & 38\end{array}$

3.2.3. Seletividade 38

3.2.4. Limite de detecção e limite de quantificação 38

$\begin{array}{ll}\text { 3.2.5. Exatidão } & 38\end{array}$

$\begin{array}{ll}\text { 3.2.6. Precisão } & 38\end{array}$

3.3. Extração e purificação da amostra empregando QUECHERS 39

3.4. Otimização da Purificação 42

4. Resultados e Discussão $\quad 44$

4.1. Linearidade 44

4.2. Sensibilidade 45 
4.3. Seletividade 45

4.4. Limite de detecção e limite de quantificação 46

$\begin{array}{ll}\text { 4.5. Exatidão } & 47\end{array}$

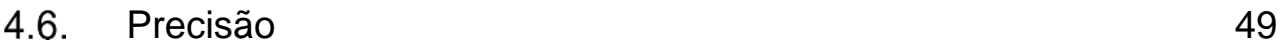

4.7. Resultados dos testes de otimização da purificação 50

5. Conclusões 58

6. Referências bibliográficas 60 


\section{Lista de figuras}

Figura 1: Fórmula estrutural dos 16 HPAs considerados prioritários pela USEPA para monitoramento ambiental.

Figura 2: Fonte Natural e Antropogênica de HPAs 19

Figura 3: Esquema de extração por Soxhlet 23

Figura 4: Esquema do equipamento de extração líquido pressurizado 25

Figura 5: Visualização das etapas de trabalho do QuEChERS. 26

Figura 6: Demonstração

das principais versões do método QuEChERS

Erro! Indicador não

definido.7

Figura 7: Esquema representativo de um cromatógrafo a líquido de alta eficiência com detecção por fluorescência (HPLC-FD) 30

Figura 8: Esquema de um GC-MS. 32

Figura 9: Fluxograma para determinar HPAs em biota usando QuEChERS. 40

Figura 10: Espectro de massa (full scan) do solvente (branco) obtido pelo GC-MS. 43

Figura 11: Espectro de massa da solução de HPAs obtido pelo GC-MS. 44

Figura 12: Recuperação do material de referência a partir do método QuEChERS. 46

Figura 13: Recuperação dos testes de otimização da purificação do método QuEChERS.

Figura 14: Espectro de massa do Teste 1 obtido pelo GC-MS. 50

Figura 15: Espectro de massa do Teste 2 obtido pelo GC-MS. 51

Figura 16: Espectro de massa do Teste 3 obtido pelo GC-MS. 52

Figura 17: Espectro de massa do Teste 4 obtido pelo GC-MS. 53

Figura 18: Espectro de massa do Teste 5 obtido pelo GC-MS. 54 


\section{Lista de tabelas}

Tabela 1: Propriedades físico-químicas dos HPAs. Número de anéis aromáticos; PM, peso molecular (g.mol-1); S, solubilidade $\left(\mathrm{mg}^{-\mathrm{L}^{-1}}\right)$; PV, pressão de vapor (Pa); $\mathrm{H}$, constante de Henry $\left(\mathrm{Pa} \mathrm{m}^{3} \cdot \mathrm{mol}^{-1}\right) ; \log \mathrm{K}_{\infty}$, coeficiente de partição (octanol/água). $\quad 21$ Tabela 2: Condições instrumentais para determinação de HPAs individuais. 37 Tabela 3: Parâmetros usados por Forsberg et al., 2011 e Johnson, 2012 para aplicação do método QuEChERS em biota marinha. 40 Tabela 4: Testes de otimização da purificação do método QuEChERS. 41 Tabela 5: Resultados obtidos para as curvas analíticas e coeficiente de correlação.

Tabela 6: Limite de Detecção e de Quantificação do Método, considerando a massa de amostra de $2,0 \mathrm{~g}$.

Tabela 7: Resultados da quantificação do material de referência NIST - 2974a usando o método QuEChERS.

Tabela 8: Coeficientes de variação dos HPAs para avaliação da precisão do método em três níveis de concentrações.

Tabela 9: Percentuais de recuperação dos testes de otimização da purificação. 48 


\section{Lista de símbolos, siglas e abreviaturas}

ANVISA - Agência Nacional de Vigilância Sanitária

$\mathrm{C}_{18}$ - Sílica modificada com hidrocarboneto linear $\mathrm{C}_{18}$, octadecilsilano

C.V - Coeficiente de variação

d-SPE - Extração em fase sólida dispersiva (do inglês dispersive solid-

phase extraction)

FD - Detecção por fluorescência (do inglês Fluorescence detection)

GC - Cromatografia Gasosa (do inglês Gas Chromatography)

$\mathrm{H}$ - Constante de Henry

HPA - Hidrocarboneto Policíclico Aromático

HPLC - Cromatografia Líquida de Alta Eficiência (do inglês High

Perfomance Liquid Chromatography)

INMETRO - Instituto Nacional de Metrologia, Qualidade e Tecnologia

Kow - Coeficiente de partição octanol/água

LD - Limite de Detecção

LQ - Limite de Quantificação

MAE - Extração assistida por micro-ondas (do inglês Microwave assisted extraction)

MS - Espectrometria de Massas (do inglês Mass Spectrometry)

PLE - Extração líquida pressurizada (do inglês Pressure liquid extraction)

PM - Peso molecular

PSA - Amina primária-secundária (do inglês Primary secondary amine)

PV - Pressão de vapor

QuEChERS - Rápido, fácil, econômico, efetivo, robusto, seguro (do inglês

quick, easy, cheap, effective, rugged and safe)

RPM - Rotação por minuto

S - Solubilidade

SFE - Extração com fluído supercrítico (do inglês Supercritical fluid extraction)

SPE - Extração em Fase Sólida (do inglês Solid-Phase Extraction)

USEPA - Agência de Proteção Ambiental dos Estados Unidos (do inglês United States Environmental Protection Agency)

UV - Ultravioleta 


\section{Introdução}

Os impactos causados ao meio ambiente pelas atividades humanas estão no centro de muitos campos de pesquisa, como a química e as ciências ambientais.

Muitas metodologias têm sido desenvolvidas para analisar compostos orgânicos em diversos tipos de matrizes ambientais, como por exemplo, água, sedimentos, atmosfera e biota. Eventualmente, as análises de amostras ambientais resultam em situações contraditórias pois causam impactos negativos no meio ambiente e nos seres humanos. Isso ocorre devido à geração excessiva de resíduos químicos, e o uso de grandes quantidades de reagentes que chegam a ser mais tóxicos que as próprias espécies químicas a ser determinadas, prejudicando não somente o meio ambiente, mas também a segurança do operador devido ao contato e a exposição aos materiais perigosos. Por consequência disso, existe uma necessidade urgente de combinar sustentabilidade com evolução tecnológica e científica para o desenvolvimento de metodologias com princípios da Química Verde (PLOTKA-WASYLKA et al.,2019).

A Química Analítica atual busca protocolos simples, rápidos, econômicos e de alto rendimento sem afetar a reprodutibilidade, representatividade, exatidão, precisão, seletividade, sensibilidade e detectabilidade. Em associação aos 12 princípios da Química Analítica Verde e com o propósito de diminuir a poluição ambiental, os pesquisadores tentam minimizar o consumo de solventes orgânicos e reagentes, reduzir a massa de amostra necessária, e fazer uso de técnicas miniaturizadas e automatizadas (GALUSKA et al., 2013).

Afim de reduzir o grande consumo de solvente, energia, tempo, substâncias químicas e outros recursos, a comunidade analítica buscou investir fortemente em metodologias de extração mais eficientes e eco-amigáveis (IBANEZ et al., 2017). Diante de uma infinidade de métodos disponíveis, o método QuEChERS (que significa rápido, fácil, barato, eficaz, robusto e seguro) ganhou grande visibilidade desde sua introdução por Anastassiades et al., 2003.

O objetivo dos desenvolvedores do QuEChERS não era apenas criar um método ambientalmente amigável e barato, mas também em uma técnica de extração eficiente que resulta em poucos interferentes (pigmentos, lipídeos, 
açúcares, ácidos graxos e etc.), seguro para instrumentação e torná-lo mais fácil para distinguir analitos de componentes endógenos (PLOTKA-WASYLKA et al.,2019).

Os hidrocarbonetos policíclicos aromáticos (HPAs) são definidos como compostos orgânicos que possuem dois ou mais anéis aromáticos de carbono e hidrogênio fundidos (CARUSO et al., 2008). Os HPAs são de grande importância ambiental e interesse toxicológico, pois são poluentes orgânicos persistentes e muitos apresentam propriedades carcinogênicas e/ou mutagênicas para homens e animais (BANSAL et al., 2015). O método QuEChERS é uma das técnicas utilizadas para a extração de HPAs, além de outras técnicas convencionais conhecidas como as de extração por Soxhlet, ultrassom, micro-ondas, líquidopressurizada.

De um ponto de vista analítico, isolar HPAs de matrizes biológicas requer na maioria das vezes uma etapa de extração mais complexa e procedimentos de purificação mais eficientes para a obtenção de extratos sem contaminantes, podendo assegurar uma análise mais precisa. Um número significativo de estudos, relatam a extração de HPAs de produtos pesqueiros utilizando extração por Soxhlet, extração assistida por micro-ondas, extração líquido pressurizado e extração com fluido supercrítico (RAMALHOSA et al., 2009).

O método QuEChERS consiste na extração com acetonitrila, particionando a matriz aquosa com $\mathrm{MgSO}_{4}$ anidro e $\mathrm{NaCl}$ seguido por uma extração dispersiva em fase sólida como etapa de purificação com $\mathrm{MgSO}_{4} \mathrm{e}$ amina secundária primária (PSA). O método é aceito mundialmente e, com poucas modificações, se tornou um método oficial da Associação dos Químicos Oficiais de Agricultura (AOAC) Internacional e do Comitê de Normalização Européia (CEN) (RAMALHOSA et al., 2009).

O QuEChERS possui grandes vantagens em relação aos outros métodos de extração convencionais. Ele permite percentuais altos de recuperação para um vasto número de analitos e, é caracterizado por resultados bastante precisos, graças ao uso de um padrão interno para eliminar os problemas, que variam os sinais nas análises de uma amostra para outra, causados geralmente por interferentes. O uso do padrão interno é importante para diminuir os erros devido às múltiplas etapas do QuEChERS. Uma outra vantagem técnica em relação aos demais métodos, é que é rápido e tem um alto rendimento da amostra, com isso, um lote de 10 a 20 amostras podem ser extraídos em 30 a 40 minutos por um único analista. O QuEChERS também está de acordo com a abordagem da Química Verde, devido seu baixo consumo de solvente e a ausência de solventes 
clorados, além de uma geração de resíduos muito pequena comparada com os métodos tradicionais de extração (REJCZAK et al., 2015).

Nesse contexto, o objetivo do trabalho é otimizar o método QuEChERS para determinar HPAs em mexilhão, utilizando os princípios básicos da Química Verde.

\subsection{Objetivo}

O objetivo deste trabalho foi otimizar um método analítico sensível para determinar hidrocarbonetos policíclicos aromáticos (HPAs) em mexilhão.

\subsection{Objetivos Específicos}

- Otimizar o método a partir de protocolos desenvolvidos para amostras de mexilhão.

- Obter um extrato com baixo teor de impurezas

- Validar o método com os parâmetros de linearidade, seletividade, sensibilidade, limite de detecção (LD), limite de quantificação (LQ), exatidão, precisão e recuperação. 


\section{Revisão Bibliográfica}

\subsection{Mexilhão}

Os moluscos são parte do maior filo de invertebrados, neles estão inclusos os mexilhões, ostras, lulas, polvos e caramujos. Esse filo se dividi em várias classes, uma delas é a classe Bivalvia, sendo representado pelos mexilhões e ostras (VIEIRA, 2012).

Os bivalves são caracterizados por serem comprimidos nas laterais e possuir uma concha composta de duas valvas, encaixadas em dobradiça dorsal que envolve o corpo todo, sendo esse, lateralmente comprimido. Eles possuem cabeça pouco desenvolvida, as brânquias são responsáveis pelas trocas gasosas e também pela captação de alimentos (VIEIRA,2012).

O mexilhão é o termo mais utilizado para se referir as diversas espécies de moluscos bivalves da família Mytilidae, sendo os gêneros mais comuns Mytilus, Perna e Mytella. Em alguns lugares e regiões, acabam recebendo nomes populares como marisco e sururu (VIERA, 2012).

O regime alimentar de um mexilhão é exclusivamente filtrador, ele consegue filtrar de 0,5 a 5 litros de água por hora, dependendo das condições ambientais e do indivíduo. O processo é contínuo, apenas sendo interrompido quando os mexilhões entram em contato com o ar. Além da função respiratória, as brânquias tem a finalidade de reter os alimentos, que são capturados através das correntes de água produzida pelos seus cílios. Sua alimentação constitui-se basicamente de fitoplanctons, bactérias e detritos orgânicos, tendo uma eficiência de retenção de partículas em suspensão na água (séston) de 100\% para partículas superiores a $4 \mu \mathrm{m}$, já as menores são capturadas com baixa eficiência (FONTES, 2011).

A assimilação de poluentes orgânicos pelos mexilhões é influenciada tanto por fatores externos, ligados diretamente à biodisponibilidade do poluente, quanto aos fatores internos do organismo. Proximidades de fontes poluidoras, temperatura, salinidade e material particulado são exemplos de fatores externos. A capacidade de metabolização seguida, ou não pela excreção do poluente são os fatores que determinam a concentração nos seus tecidos. No geral, os 
mexilhões apresentam uma rápida assimilação dos poluentes orgânicos enquanto que sua excreção dos mesmos é de forma lenta (FONTES, 2011).

A partir disso, o mexilhão tem sido recomendado por muitos pesquisadores como o melhor organismo para biomonitorar o ambiente marinho, uma vez que tem a característica de filtrar grandes volumes de água estando exposto à substâncias tóxicas solúveis ou associadas a materiais particulados (DEMARCO, 2017). Por outro lado, esses animais são fontes de alimentos comercialmente importantes para áreas costeiras, e o consumo deles quando contaminados com HPAs, podem gerar graves problemas aos consumidores. Por isso, são importantes os métodos capazes de determinar e averiguar esses contaminantes em baixas concentrações.

A respeito sobre sua composição centesimal $\left(\mathrm{g}_{\left.100 \mathrm{~g}^{-1}\right)}\right.$ do mexilhão Perna, de acordo com FURLAN et al. (2011) relataram em seus estudos valores de umidade de $83,8 \%$, proteína $9,1 \%$, lipídeos $1,1 \%$, carboidratos $4,2 \%$ e teor de cinzas de 1,8\%. Para a mesma espécie, CORDEIRO et al. (2007), obtiveram valores para umidade de $85,8 \%$, proteína $7,1 \%$, lipídeos $1,2 \%$, carboidratos $3,8 \%$ e teor de cinzas 1,9\%. Levando em consideração a composição centesimal, podese dizer que o mexilhão é uma importante fonte proteíca e de baixo teor lipídico. Porém, suas variações percentuais são afetadas por sazonalidade, alimentação e condições fisiológicas (FURLAN et al., 2011).

\subsection{Hidrocarbonetos policíclicos aromáticos (HPAs)}

Os hidrocarbonetos policíclicos aromáticos (HPAs) são compostos orgânicos constituídos de dois ou mais anéis de benzeno fundidos arranjados em diversas configurações. (ZHANG et al., 2016). Os HPAs podem ser encontrados nas mais diversas matrizes ambientais como ar, água, solo, sedimento, bem como em produtos e resíduos da indústria petroquímica. São motivo de preocupação para o meio ambiente devido aos seus efeitos tóxicos e cancerígenos. Suas estruturas estáveis permitem que eles persistam no ambiente por muito tempo até outros derivados do petróleo degradarem (BOJES et al., 2007).

Estima-se a existência de mais de 100 diferentes tipos de HPAs no ambiente, na Figura 1 são apresentados os 16 HPAs considerados prioritários de acordo com as Diretrizes para a Avaliação de Risco Carcinogênico da Agência de Proteção Ambiental dos Estados Unidos (USEPA - United State Environmental Protection Agency). Devido aos seus impactos negativos no ambiente e na saúde humana, esses compostos são de extrema importância no monitoramento 
ambiental de poluentes orgânicos prioritários (USEPA, 2005). Destes HPAs, a USEPA considera 7 como prováveis carcinógenos humanos, são eles: benzo[a]antraceno, criseno, benzo[a]pireno, benzo[b]fluoranteno, benzo[k]fluoranteno, dibenzo[a,h]antraceno, indeno[1,2,3-cd]pireno (NTP, 2005).

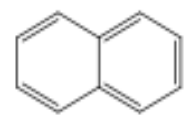

Naftaleno

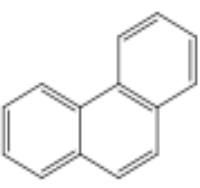

Fenantreno

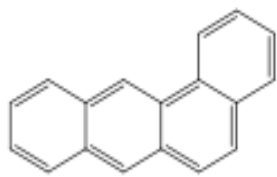

Benzo[a]antraceno

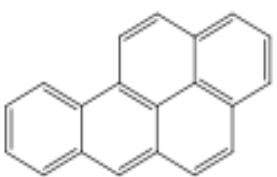

Benzo[a]pireno

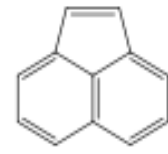

Acenaftileno

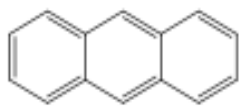

Antraceno

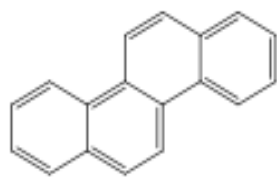

Criseno

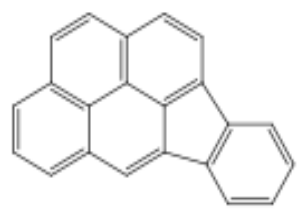

Indeno[1,2,3-cd]pireno

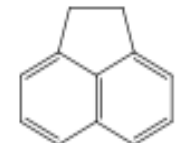

Acenafteno

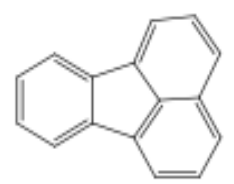

Fluoranteno

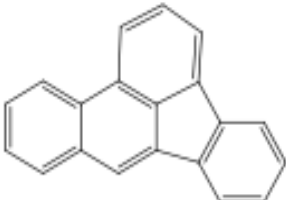

Benzo[b]fluoranteno

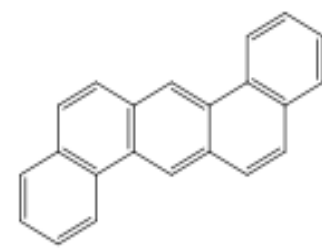

Dibenzo[a,h]antraceno

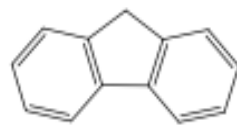

Fluoreno

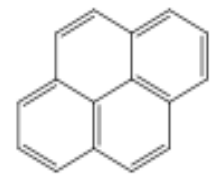

Pireno

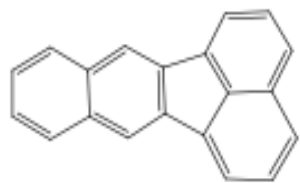

Benzo[k]fluoranteno

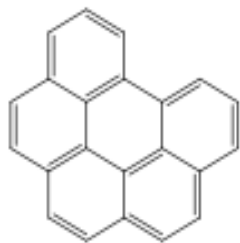

Benzo[g,h,i]perileno

Figura 1 - Fórmula estrutural dos 16 HPAs considerados prioritários pela USEPA para monitoramento ambiental.

\subsection{Fontes}

As principais fontes de HPAs no meio ambiente são a pirogênica e a petrogênica. Ambas são de origem antropogênica, estão associadas diretamente à influência do ser humano no ambiente e que originam principalmente, assim como as fontes naturais, HPAs de origem pirolítica e petrogênica (NEFF, 2001).

Os HPAs pirogênicos são formados pela combustão incompleta da matéria orgânica quando submetida a temperaturas elevadas $\left(>700^{\circ} \mathrm{C}\right)$ e esse processo se caracteriza por formar principalmente compostos de 4 a 6 anéis aromáticos não substituídos. Em relação às fontes naturais, esses HPAs são formados a partir das queimadas e erupções vulcânicas, já sob o domínio de fontes antrópicas são originados da queima de combustíveis fósseis e florestas, 
incineração de resíduos, processos industriais e emissão de motores (DEMARCO, 2017).

O principal meio de transporte dos HPAs pirolíticos é por via atmosférica associados a materiais particulados finos, a qual permite uma grande concentração desses compostos no ambiente. Os HPAs uma vez na atmosfera, podem ser depositados em forma seca ou úmida sobre sistemas aquáticos e terrestres (MEIRE et al., 2007).

Os HPAs também podem ser formados em baixas temperaturas. Em respeito a isto, os HPAs que são formados durante a maturação do petróleo e processos semelhantes, são chamados de HPAs petrogênicos (ABDEL-SHAFY et al., 2015).

Os HPAs petrogênicos se caracterizam por estar em geral em maior abundância no meio ambiente e por possuir em sua estrutura molecular 2 a 3 anéis benzênicos (LIGUORI et al., 2006). Esses compostos petrogênicos são naturalmente liberados para o meio ambiente, e em especial no meio marinho, através da exsudação do petróleo a partir do assoalho oceânico. As fontes antrópicas são geradas a partir do transporte e do processamento do petróleo, armazenamento irregular de óleo e do descarte de combustíveis, uso dos produtos derivados do petróleo, exploração do petróleo em mar ou terra, derramamento direto de óleo no oceano, como no caso de acidentes com navios tanques e dutos (NEFF, 2001). A Figura 2 mostra a maneira que os HPAs se formam.

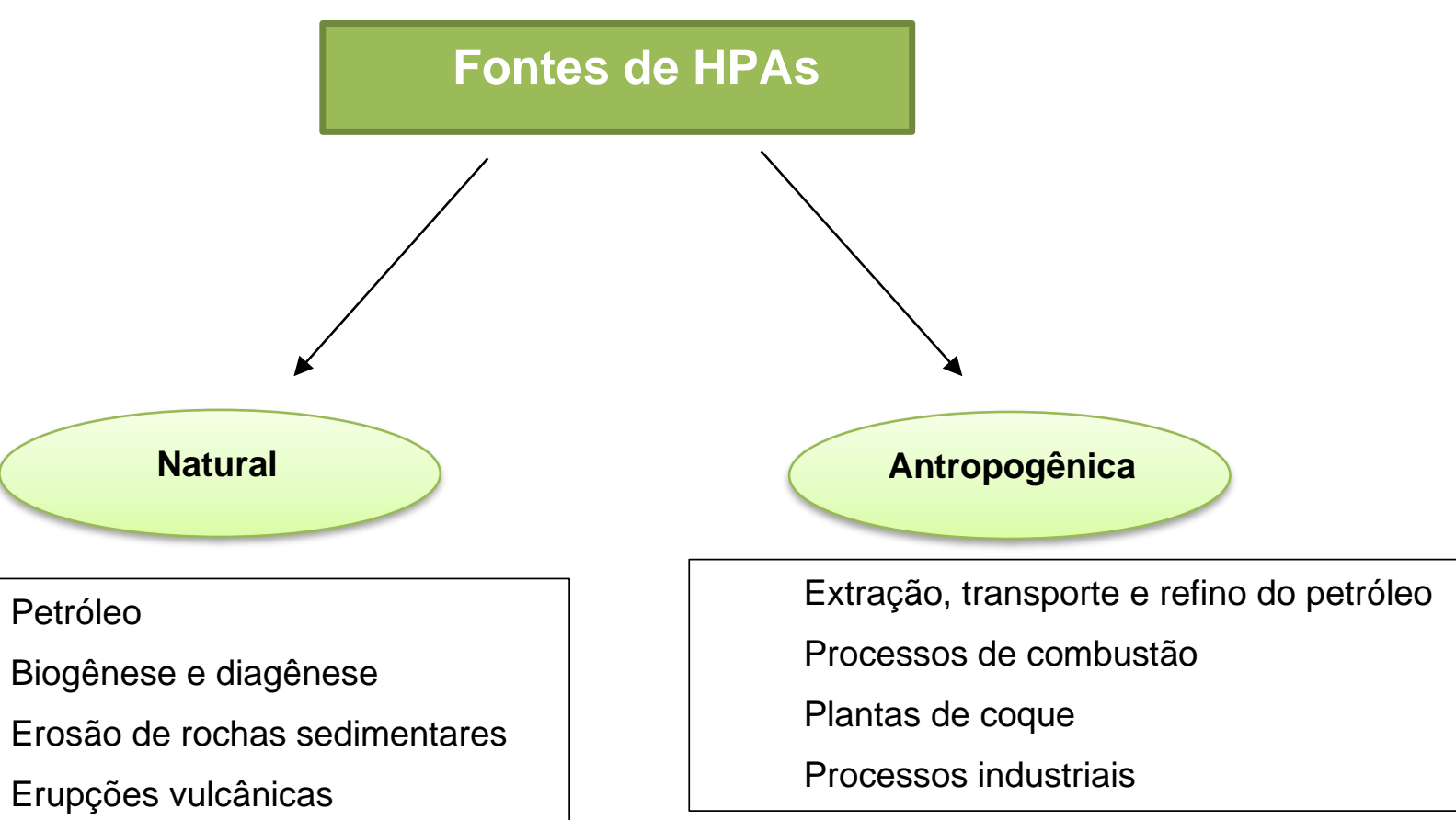


Figura 2 - Fonte Natural e Antropogênica de HPAs (Fonte: Adaptado de ABDEL-SHAFY, 2016)

\subsection{Propriedades físico-químicas}

Através de suas propriedades químicas e físicas, os HPAs auxiliam na distribuição e avaliação dos mesmos em vários compartimentos ambientais (solo, sedimento, atmosfera e água), assim como efeitos adversos causados aos seres humanos e ao meio ambiente (SISINNO et al., 2013)

A solubilidade e a pressão de vapor, são importantes fatores pois conduzem a distribuição desses contaminantes entre as fases solúvel e particulada em meio aquoso, atmosférico e biótico. Em água a solubilidade varia entre os mais insolúveis a pouco solúveis, respectivamente benzo[g,h,i]perileno $\left(0,003 \mathrm{mg} \mathrm{L}^{-1}\right)$ e naftaleno (31 $\left.\mathrm{mg} \mathrm{L}^{-1}\right)$. Por outro lado, a pressão de vapor varia entre os compostos mais voláteis (naftaleno) e compostos poucos voláteis (dibenzo[a,h]antraceno), a Tabela 1 apresenta os respectivos valores da pressão de vapor para os HPAs. Apresentam alto coeficiente de partição entre solventes orgânicos e água, no qual nos permite presumir possíveis processos cumulativos em compartimentos como solo e sedimentos, e, também a bioacumulação em sistemas biológicos (MEIRE et al., 2007).

Na Tabela 1, também pode se observar que o peso molecular dos HPAs é inversamente proporcional à solubilidade, que diminui com o aumento do número de anéis. Os HPAs apresentam características lipofílicas que podem ser de moderada até altamente lipossolúveis, onde apresentam coeficiente de partição octanol-água (log Kow) que variam entre 3,37 a 6,75. Além disso, a volatilidade desses compostos pode ser relacionada com o peso molecular, os que possuem menores pesos consequentemente apresentarão elevada pressão de vapor e uma ampla distribuição no ambiente (MEIRE et al., 2007). 
Tabela 1 - Propriedades físico-químicas dos HPAs. Número de anéis aromáticos; $\mathrm{PM}$, peso molecular (g.mol$\left.{ }^{-1}\right)$; S, solubilidade $\left(\mathrm{mg}^{\mathrm{L}} \mathrm{L}^{-1}\right)$; PV, pressão de vapor (Pa); $\mathrm{H}$, constante de Henry $\left(\mathrm{Pa} \mathrm{m}^{3} \cdot \mathrm{mol}^{-1}\right)$; Log $\mathrm{K}_{\mathrm{ow}}$, coeficiente de partição (octanol/água). (Fonte: Adaptado de LATIMER \& ZHENG, 2003)

\begin{tabular}{ccccccc}
\hline HPAs & $\begin{array}{c}\text { No de } \\
\text { anéis }\end{array}$ & $\mathbf{P M}\left(\mathbf{g} \cdot \mathbf{m o l}^{-1}\right)$ & $\begin{array}{c}\mathbf{S} \\
\left(\mathbf{m g} \cdot \mathbf{L}^{-1}\right)\end{array}$ & $\mathbf{P V}(\mathbf{P a})$ & $\begin{array}{c}\mathbf{H}(\mathbf{P a} \\
\left.\mathbf{m}^{3} \cdot \mathbf{m o l}^{-1}\right)\end{array}$ & $\begin{array}{c}\mathbf{L o g} \\
\mathbf{K}_{\text {ow }}\end{array}$ \\
\hline Naftaleno & 2 & 128 & 31 & 10,4 & 43,01 & 3,37 \\
\hline Acenaftileno & 3 & 150 & 16,1 & 0,9 & 8,4 & 4,00 \\
\hline Acenafteno & 3 & 154 & 3,8 & 0,3 & 12,17 & 3,92 \\
\hline Fluoreno & 3 & 166 & 1,9 & 0,09 & 7,87 & 4,18 \\
\hline Fenantreno & 3 & 178 & 1,1 & 0,02 & 3,24 & 4,57 \\
\hline Antraceno & 3 & 178 & 0,045 & 0,001 & 3,96 & 4,54 \\
\hline Fluoranteno & 4 & 202 & 0,26 & 0,00123 & 1,037 & 5,22 \\
\hline Pireno & 4 & 202 & 0,132 & 0,0006 & 0,92 & 5,18 \\
\hline Benz[a]antraceno & 4 & 228 & 0,011 & $2,80.10^{-5}$ & 0,581 & 5,91 \\
\hline Criseno & 4 & 228 & $\mathrm{ND}$ & $5,70.10^{-7}$ & 0,065 & 5,86 \\
\hline Benz[b]fluoranteno & 5 & 252 & 0,0015 & $\mathrm{ND}$ & $\mathrm{ND}$ & 5,80 \\
\hline Benz[k]fluoranteno & 5 & 252 & 0,0008 & $5,20.10^{-8}$ & 0,016 & 6,00 \\
\hline Benzo[a]pireno & 5 & 252 & 0,0038 & $7,00.10^{-7}$ & 0,046 & 6,04 \\
\hline Indeno[1,2,3-cd]pireno & 6 & 278 & $\mathrm{ND}$ & $\mathrm{ND}$ & 0,003 & $\mathrm{ND}$ \\
\hline Dibenzo[a,h]antraceno & 5 & 278 & 0,0006 & $3,70.10^{-10}$ & $\mathrm{ND}$ & 6,75 \\
\hline Benzo[g,h,i]perileno & 6 & 268 & 0,00026 & $\mathrm{ND}$ & 0,075 & 6,50 \\
\hline & & $\mathrm{ND}-\mathrm{Não}$ determinado & & &
\end{tabular}

\subsection{Determinação de HPAs}

A determinação de HPAs é constituída de três etapas primordiais, que são a extração dos analitos, a purificação do extrato e a determinação dos analitos empregando técnicas instrumentais. A etapa de extração da amostra tem como foco principal extrair componentes de interesse presentes na matriz, que podem interferir na determinação instrumental (LANÇAS et al., 2008). 
Para as amostras de matrizes mais complexas, como por exemplo amostras ambientais, alimentos, fluidos biológicos, é fundamental a purificação do extrato, uma vez que nessa etapa, o objetivo é a eliminação de um maior número possível de interferentes, o que ajudará em uma melhor seletividade durante a análise (CALDAS et al., 2013).

Em alguns casos, mesmo seguindo processos rigorosos de pré-tratamento da amostra, a fração desejada pode ainda conter centenas de compostos. Logo, é necessário a implementação de métodos analíticos que combinem boa resolução e sensibilidade (ASTDR, 2015). Portanto, têm sido utilizadas para determinação de HPA a cromatografia em fase gasosa, cromatografia líquida de alta eficiência e cromatografia em camada delgada. A que provê a melhor separação, seletividade e possibilidade de identificação dos compostos dentre as três mencionadas é a cromatografia a gás acoplada a detector de espectrometria de massas (GC-MS) (CROMPTON, 1984; POSTER et al., 2006).

\subsection{Métodos analíticos para extração de HPAs}

\subsubsection{Extração por Soxhlet}

A extração por Soxhlet é uma técnica bastante empregada e em geral usada como padrão de extração de HPAs com recuperação de quase $100 \%$. Também é utilizada como referência quando métodos alternativos necessitam de avaliação. (CHEMO., 2003; WANG et.al, 2006). O método de extração por Soxhlet consiste em extrair compostos semi-voláteis e não-voláteis de matrizes sólidas em um processo lento, que demanda grandes volumes de solventes (USEPA, 2008).

A técnica é caracterizada pela adição de uma amostra sólida em um recipiente poroso chamado dedal (cartucho de celulose ou de vidro), este é colocado na câmara principal do extrator Soxhlet. O extrator é conectado a um balão de fundo redondo contendo o solvente, no qual é aquecido em uma manta de aquecimento. O solvente é aquecido e o vapor gerado sobe pelo tubo lateral até o condensador, onde sofre condensação, gotejando no extrator e cobrindo o dedal. Quando o nível do solvente atingir o sifão, o solvente é sifonado pelo braço lateral, levando consigo as substâncias solúveis. O processo se repete enquanto o sistema ficar em aquecimento (algumas horas), com o objetivo de retirar seus compostos alvo da matriz que está sendo extraída. Após resfriamento, o solvente pode ser evaporado por destilação e reciclado. A Figura 3 abaixo demonstra o esquema de um sistema para extração via Soxhlet. (BECKER et al., 1997). 


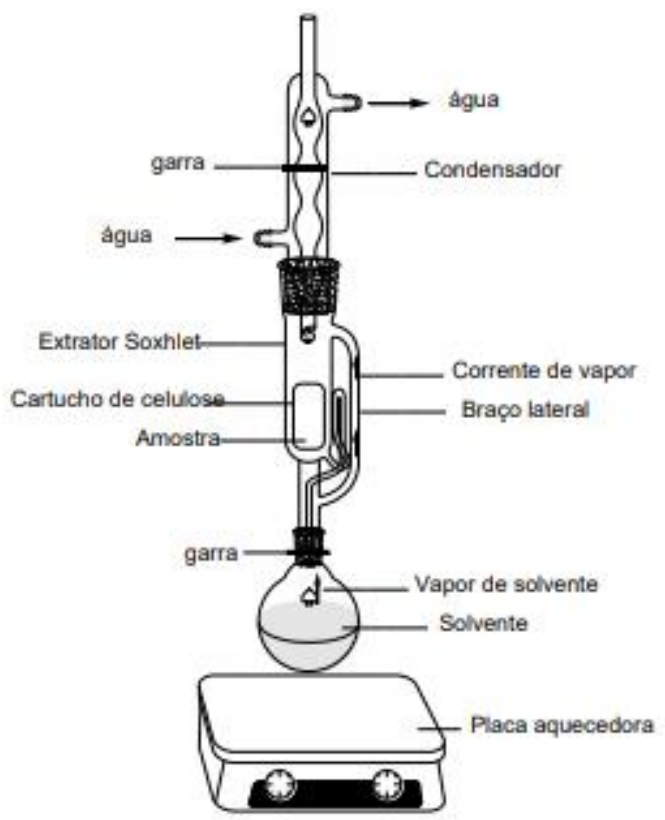

Figura 3 - Esquema de extração por Soxhlet. (Fonte: BECKER et al., 1997)

VIVES et al. (2004) analisaram HPAs em fígado de peixe, usando o método de extração por Soxhlet. Os fígados dos peixes foram removidos e armazenados até serem analisados. No processo de extração, o fígado foi misturado com sal ativo e moído e posteriormente foi fortificado com HPAs deuterados. A extração por Soxhlet foi realizada em $20 \mathrm{~h}$ usando como solvente hexano e diclorometano $(4: 1, v / v)$. Na etapa de clean-up, uma coluna cromatográfica de óxido de alumínio com hexano e diclorometano $(1: 2, \mathrm{v} / \mathrm{v})$ foi utilizada. Para esse estudo as recuperações de HPAs obtidas foram de $39 \%$ a $117 \%$.

YOSHIMINE et al. (2012) determinaram 16 HPAs prioritários de acordo com a USEPA em amostras de mexilhão coletadas em fazenda, utilizando GCMS. Foram utilizadas $3 \mathrm{~g}$ de amostra, na qual foram extraídas usando o método de extração por Soxhlet durante 24h utilizando um volume de $200 \mathrm{~mL}$ de diclorometano como solvente e p-terfenil- $\mathrm{D}_{14}$ como surrogate. Os extratos foram purificados em duas etapas, a primeira com uma coluna de vidro contendo $20 \mathrm{~g}$ de alumina neutra e eluição com $100 \mathrm{~mL}$ de diclorometano e a segunda etapa por cromatografia por permeação em gel (GPC), usando um sistema Shimadzu LC10, uma coluna Shodex CLNpak EV2000 e uma mistura de acetona:ciclohexano (3:1, v/v). Os HPAs foram isolados do extrato purificado por cromatografia de adsorção, utilizando uma coluna de $7 \mathrm{~g}$ de alumina, $10 \mathrm{~g}$ de sílica-gel, $1 \mathrm{~g}$ de sulfato de sódio e no topo $1 \mathrm{~g}$ de cobre ativado para remoção de enxofre. Os HPAs foram isolados 
na segunda fração e eluidos com $100 \mathrm{~mL}$ de uma mistura de diclorometano e hexano $(1: 1, v / v)$. O volume foi evaporado por rota evaporador e ajustado para 1 $\mathrm{mL}$ em um vial e então direcionado para a quantificação no GC-MS.

\subsubsection{Extração assistida por micro-ondas}

A extração assistida por micro-ondas (MAE) é o processo no qual é usado energia de micro-ondas para aquecer o solvente que está em contato com a amostra para que o analito desejado seja separado da amostra para o solvente (ESKILSSON et al., 2000). Esse tipo de método permite que os compostos orgânicos e também os organometálicos sejam extraídos rapidamente e seletivamente com a mesma recuperação ou até melhores do que as extrações por técnicas convencionais (PARE et al., 1994). O sistema de aquecimento é baseado na interação do campo elétrico com as moléculas do material, sendo que este pode ser gerado de duas formas, condução iônica ou rotação dipolo. No caso de condução iônica, o calor é gerado de acordo como o meio se opõe ao fluxo de íons, com isso o fluxo de íons causa colisões entre as moléculas e isso também gera calor (LETELLIER et al., 1999).

Essa técnica oferece algumas vantagens em comparação às técnicas convencionais, é de fácil automação, apresenta tempo menor de análise, baixo consumo de solvente, com consequente prevenção da poluição nos laboratórios, baixo custo e devida atenção aos constituintes termolábeis (MANDAL et al., 2007).

A partição dos compostos depende da natureza da matriz e do solvente. $A$ energia micro-ondas proporciona o aquecimento paralelo de toda amostra sem aquecer o recipiente, em decorrência disso, a solução alcança o ponto de ebulição imediatamente, reduzindo o tempo de extração. Comumente, o solvente utilizado precisa ter elevada constante dielétrica relativa, de modo que possa absorver vigorosamente a energia micro-ondas. Ainda assim, em situações com compostos termolábeis, a matriz é a única que pode ser aquecida, e os analitos são liberados em solvente frio, ou seja, com constante dielétrica menor, evitando assim sua degradação (CAMEL, 2000).

PENA et al., (2006) avaliaram e desenvolveram um procedimento de extração por micro-ondas para extrair 6 HPAs em amostra de peixe. $O$ trabalho realizou a otimização do tempo de extração, volume de solvente e a influência da temperatura. A partir dos resultados obtidos foi possível concluir que a 
temperatura, o tempo de extração e o volume de solventes afetam o rendimento de extração de HPAs.

\subsubsection{Extração líquido pressurizada}

Esse método também conhecido como extração acelerada por solvente do inglês Accelerated Solvent Extraction, tem sido usado para remover analitos em amostras sólidas desde 1955 (BJORKLUND et al., 2000). A necessidade de trabalhar em altas temperaturas faz com que o solvente reduza sua resistência à força, aumentando a taxa de difusão do analito da amostra para o solvente. O aumento da pressão induz que o solvente alcance áreas na amostra que não seriam de fácil acesso caso se trabalhasse em condições padrão (CAMEL, 2001).

Para garantir que todos os analitos sejam extraídos durante o processo de extração, um novo solvente deve ser colocado na câmara de extração, produzindo então uma distribuição desigual de soluto na solução, consequentemente aumentando a taxa de difusão (RICHTER et al., 1996).

O procedimento de extração pode ser descrito da seguinte forma, a célula de extração é colocada na posição vertical e dentro da célula adiciona-se a amostra, após essa etapa, o solvente de extração é inserido na célula através do tubo de solvente. A célula é levada a uma temperatura entre $150^{\circ} \mathrm{C}$ a $200^{\circ} \mathrm{C}$ e pressurizada a um valor definido de pressão por 5-10 minutos. Em seguida o solvente é retirado e colocado em um frasco para que seja inserido um novo solvente na célula para remover qualquer analito restante. Por fim, o gás nitrogênio é utilizado para purgar a célula e remover o solvente (BJORKLUND et al., 2000). A Figura 4 ilustra um esquema do equipamento de extração líquido pressurizado.

HAWTHORNE et al., (2000) descobriram que mesmo a extração líquida pressurizada tenha uma vantagem de analisar muitas amostras ao mesmo tempo. O tempo para uma extração é muito curto e o extrato poucas vezes requer limpeza antes da análise cromatográfica. 


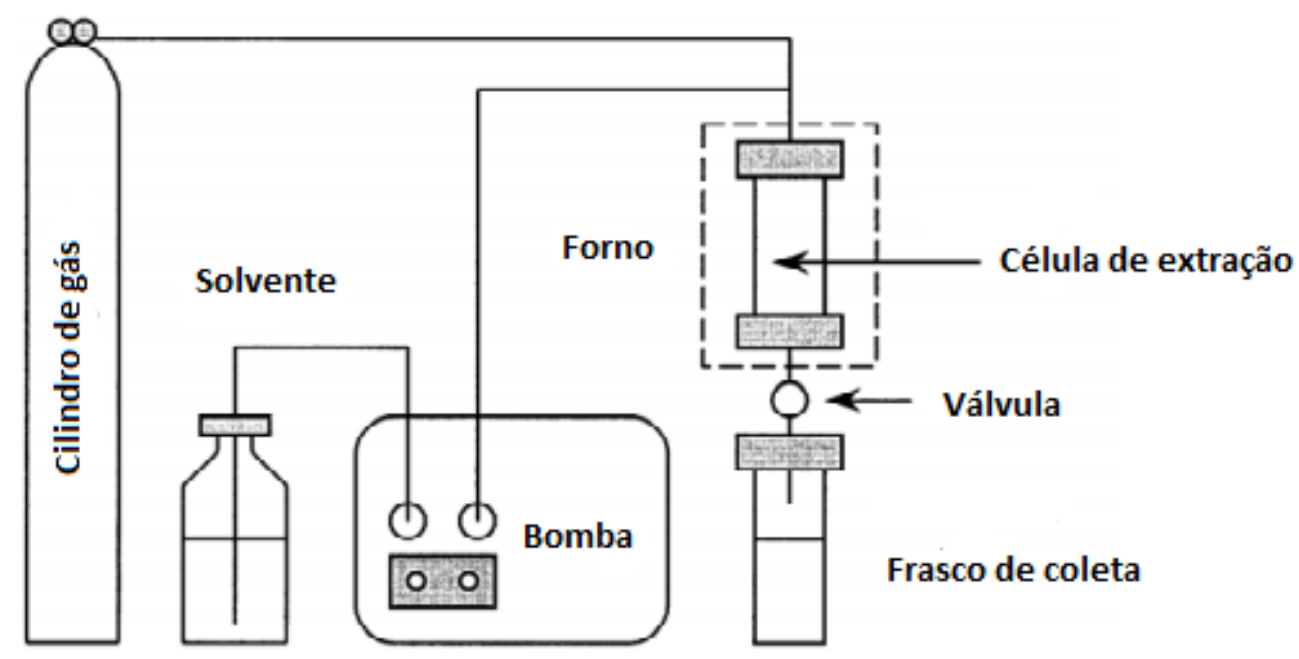

Figura 4 - Esquema do equipamento de extração líquido pressurizado. (Fonte: Adaptado de BJORKLUND et al., 2000)

\subsubsection{Extração por QuEChERS}

Em 2003, uma abordagem que denominaram de rápida, fácil, barata, eficaz, robusta e segura (QuEChERS, acrônimo de Quick, Easy, Cheap, Effective, Rugged and Safe) foi desenvolvida por ANASTASSIADES et al. (2003), onde é possível englobar etapas de extração, partição e purificação do extrato em único procedimento. Caracterizado pelo uso da acetonitrila na extração, seguido da adição de sais $\left(\mathrm{NaCl}\right.$ e $\left.\mathrm{MgSO}_{4}\right)$ que promovem o efeito salting out e facilitam a partição das fases aquosa e orgânica. Posteriormente a etapa de limpeza do extrato caracterizada por uma nova técnica de extração em fase sólida dispersiva (d-SPE, do inglês dispersive solid-phase extraction), onde nesta etapa uma alíquota do sobrenadante é colocada em contato com sais e sorventes que são agitados e centrifugados para se obter um extrato com um menor teor de impurezas. A Figura 5 demonstra as etapas de trabalho do método QuEChERS. 


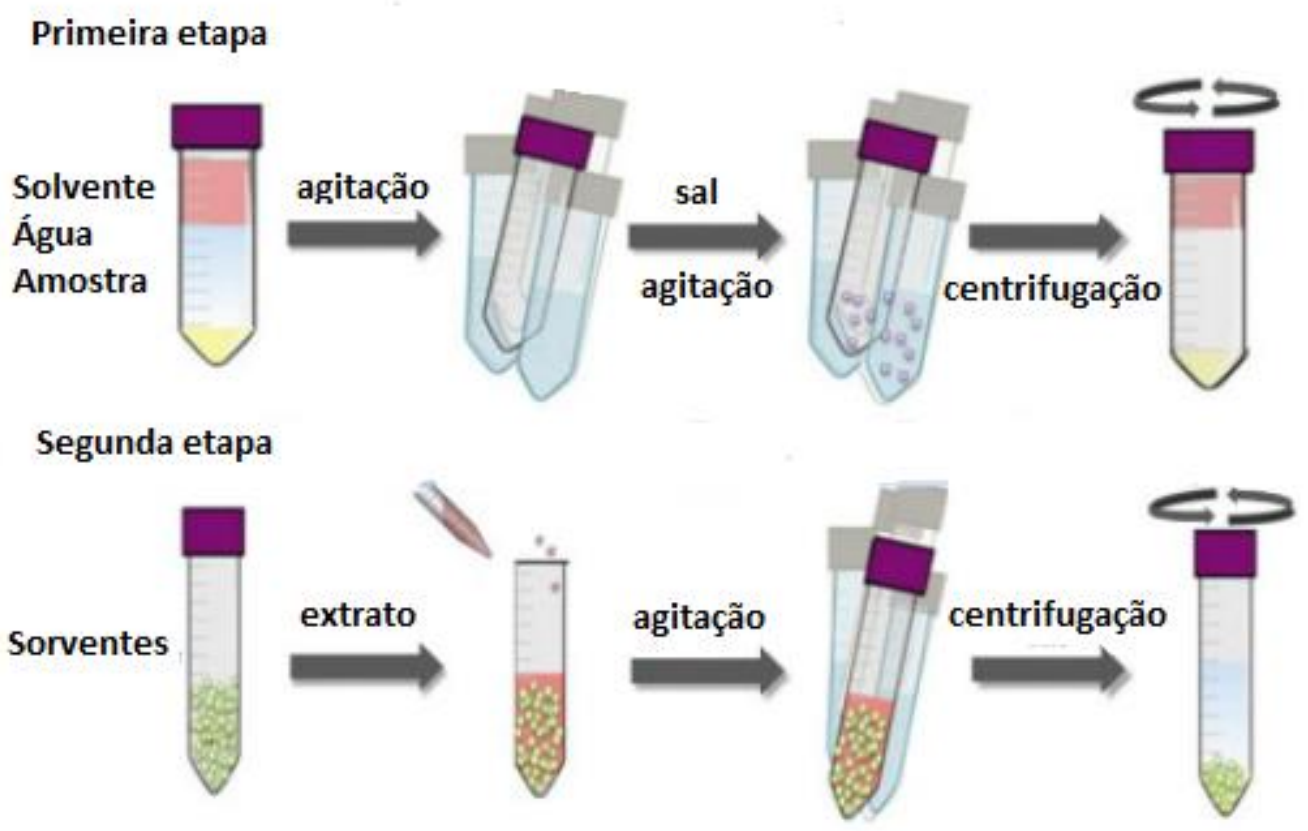

Figura 5 - Visualização das etapas de trabalho do QuEChERS. (Fonte: PLOTKA-WASYLKA et al.,2019).

Segundo MORRISON et al. (2016), devido à facilidade e procedimentos de limpeza adaptáveis, o método vem sendo bastante utilizado em análises multiclasse de diferentes compostos em diversas amostras, trazendo bons percentuais de recuperação. O método QuEChERS diminui a complexidade do processo analítico reduzindo o volume de solvente utilizado, além de reduzir o tempo de preparação da amostra, utilizando poucas vidrarias para que a limpeza após a extração seja mais fácil e rápida, sendo também bastante eficiente para a extração do analito da amostra (ANASTASSIADES et al., 2003). Este método está sendo usado para a extração de vários compostos como pesticidas e HPAs de amostras sólidas (KALACHOVA et al., 2011).

A extração por QuEChERS pode sofrer algumas modificações devido os analitos apresentarem problemas de estabilidade com o $\mathrm{pH}$ da matriz, com isso foram implementadas adaptações do método, neste caso a inclusão de uma etapa de tamponamento. LEHOTAY et al. (2005) propôs o método QuEChERS acetato, fundamentado no uso de acetonitrila em meio ácido, incluindo uma etapa de tamponamento com pH 4,8, obtido pela adição de acetato de sódio proporcionando o aumento do percentual de recuperação dos compostos que dependem do pH. Por outro lado, ANASTASSIADES et al. (2007) sugeriram o método QuEChERS citrato, onde uma mistura de citrato de sódio di e sesquiidratados são encarregados pelo tamponamento para manter o pH em uma 
faixa de 5,0 a 5,5. Abaixo uma demonstração dos procedimentos das principais versões deste método QuEChERS podem ser observadas na Figura 6.

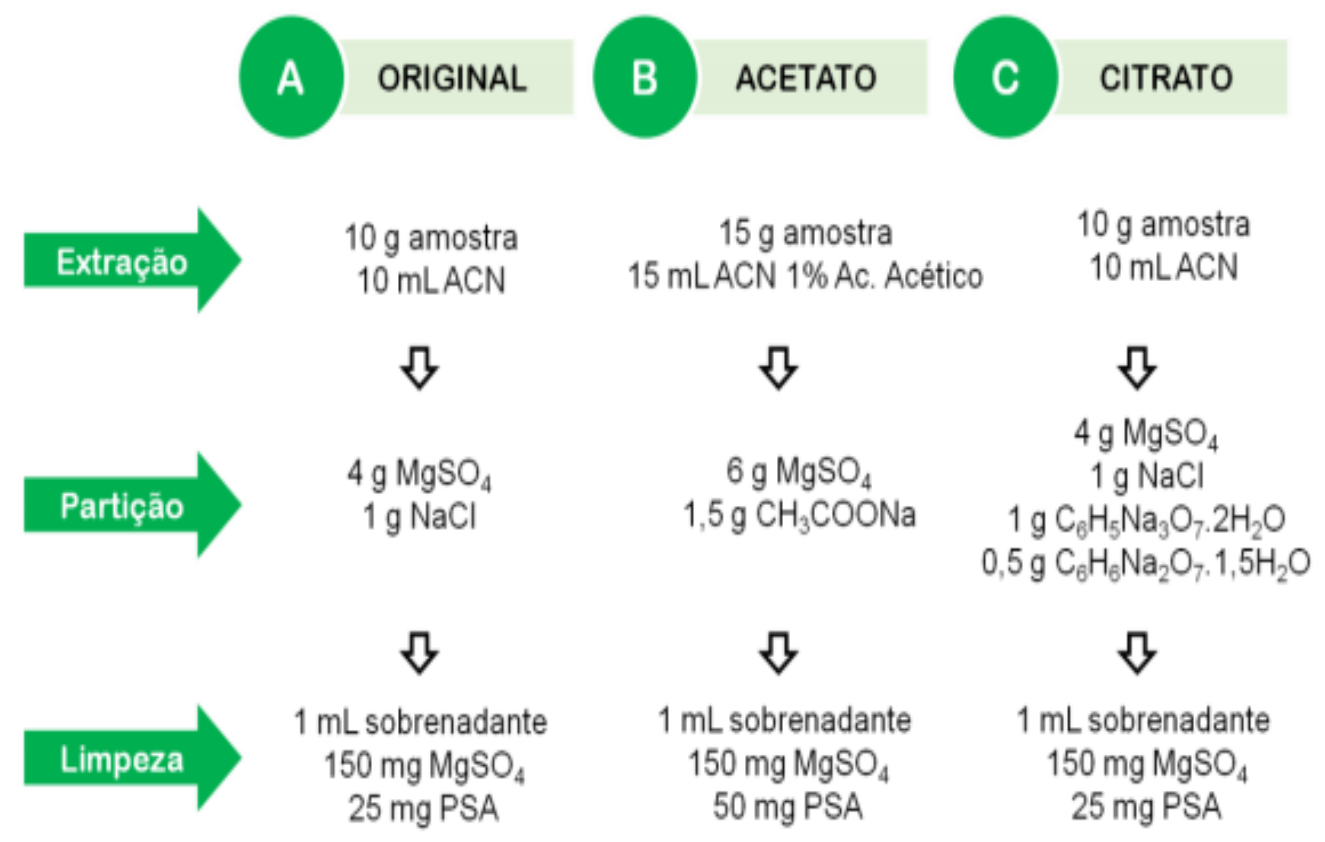

Figura 6 - Demonstração das principais versões do método QuEChERS (Fonte: DEMARCO, 2017).

Devido sua alta flexibilização de execução, vários sorventes podem ser utilizados na etapa de limpeza do extrato por d-SPE antes do mesmo ser injetado no sistema cromatográfico promovendo a integridade do equipamento e diminuindo ou removendo os possíveis interferentes da matriz. O tipo de sorvente é depende totalmente da amostra a ser analisada, dos analitos de interesse e dos interferentes no extrato. O PSA (amina primária-secundária) é um sorvente indicado para remoção de ácidos graxos, ácidos orgânicos, pigmentos e carboidratos, uma vez que seus grupos amino primário e secundário em sua estrutura apresentam efeito quelante sob os interferentes. Por outro lado, amostras com alto teor de lipídios e ácidos graxos necessita-se de sorventes apolares, como por exemplo o $\mathrm{C}_{18}$ (DEMARCO, 2017).

O método QuEChERS foi utilizado por RAMALHOSA et al. (2009) para analisar HPAs em amostras de peixe. As recuperações para esse experimento foram de 63,5 a $110 \%$, sendo analisados 16 HPAs. No procedimento experimental, $5 \mathrm{~g}$ de amostra foram colocados em tubos de teflon de $50 \mathrm{~mL}$, com adição de $6 \mathrm{~g}$ de $\mathrm{MgSO}_{4}$ e 1,5 g de NaOAc como sais de partição. Para a etapa de limpeza, 300 mg PSA, 150 mg C 18 e 900 mg de MgSO $_{4}$ foram usados em um 
tubo de teflon de $15 \mathrm{~mL}$. Por fim, a análise foi realizada através de cromatografia líquida com detector de fluorescência.

MADUREIRA et al. (2014) analisaram 16 HPAs em amostras de mexilhão utilizando GC-MS/MS via QuEChERS. Foram extraídas $10 \mathrm{~g}$ de amostra com 10 $\mathrm{ml}$ de acetonitrila. Na partição foram utilizados $4 \mathrm{~g}$ de $\mathrm{MgSO}_{4}$ e $1 \mathrm{~g}$ de $\mathrm{NaCl}$. O clean-up do extrato por d-SPE utilizou $150 \mathrm{mg}$ de PSA e $900 \mathrm{mg}$ de $\mathrm{MgSO}_{4}$ para $6 \mathrm{~mL}$ de extrato. As recuperações ficaram entre 89 a 112\%

ANGIONI et al. (2012) realizaram análises em amostras de ouriço-do-mar por GC-MS/MS para analisar 17 HPAs. A análise foi realizada com $1 \mathrm{~g}$ de amostra e $1 \mathrm{~mL}$ de acetonitrila, a etapa de partição empregou-se os sais $\mathrm{MgSO}_{4}$ e acetado de sódio. A etapa de limpeza do extrato por d-SPE utilizou-se PSA, $\mathrm{C}_{18}$ e $\mathrm{MgSO}_{4}$. Foi obtido uma recuperação de 70 a $120 \%$.

\subsection{Técnicas cromatográficas para determinar HPAs}

Usualmente a determinação de HPAs é realizada por cromatografia líquida de alta eficiência (HPLC, do inglês high performance liquid chromatography) ou por cromatografia em fase gasosa (GC, do inglês gas chromatography) (PLAZABOLAÑOS, FRENICH \& VIDAL, 2010).

\subsubsection{Cromatografia a líquido de alta eficiência (HPLC)}

Por ser uma técnica muito utilizada em análises de HPAs, a HPLC possibilita a separação com eficiência das espécies, promovendo determinações precisas e com boa detecção (SILVA, 2013). Nesta técnica cromatográfica os detectores mais usados são os de ultravioleta (UV) e de fluorescência (FD), sendo que a detecção por UV quando comparada à FD, possui algumas desvantagens, como problemas com seletividade e limitação de detectibilidade. Além disso, em amostras como alimentos, que por sua vez são matrizes complexas, o detector UV não consegue discriminar entre analitos e interferentes (LAI \& FRANKE,2013).

O HPLC-FD consiste no equipamento HPLC com um detector de fluorescência que é ajustado em diferentes comprimentos de onda de excitações e emissões para dispor de diferentes energias de absorção dos HPAs. Em ótimas condições tem a capacidade de alcançar limites de detecção no nível de picogramas $\left(10^{-12}\right)$ (LAI \& FRANKE, 2013). 
Os compostos fluorescentes espontaneamente são relativamente raros e incluem aqueles que possuem pelo menos duas ligações conjugadas (doadores de elétrons) ou grupos específicos capazes de doarem elétrons para um sistema e por decorrência aumentar a intensidade de fluorescência. Já os compostos não fluorescentes são prováveis de conseguir essa característica por reações pré ou pós-coluna. No caso do HPAs, eles apresentam fluorescência molecular devido sua estrutura eletrônica, e por sua vez, essa propriedade contribui para a sua detecção nos mais diversos tipos de matrizes e com alta sensibilidade (NETTO et al., 2000). A Figura 7 apresenta um esquema de HPLC com detecção por fluorescência.

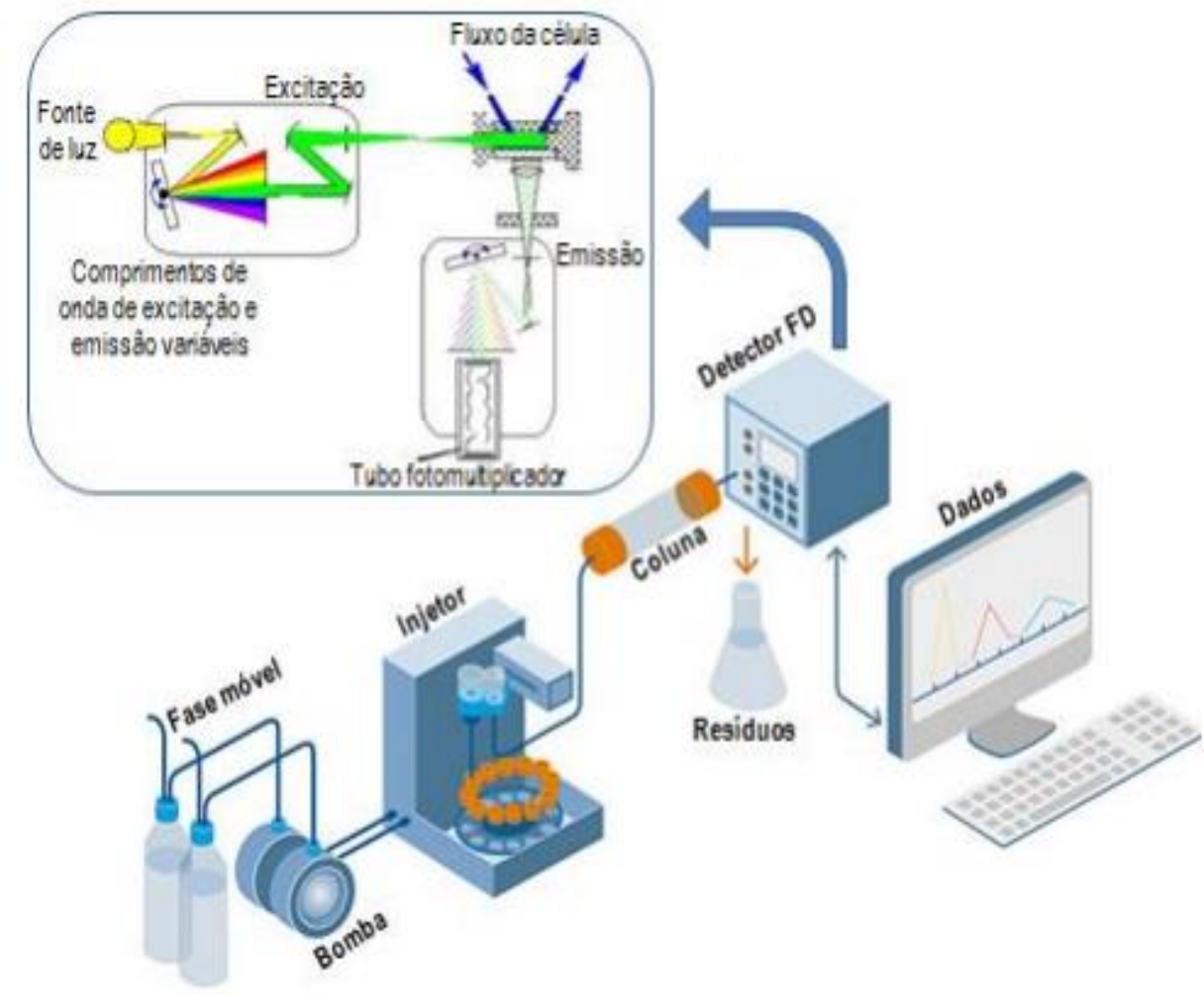

Figura 7 - Esquema representativo de um cromatógrafo a líquido de alta eficiência com detecção por fluorescência (HPLC-FD) (Fonte: Demarco, 2017)

\subsubsection{Cromatografia em fase gasosa (GC) - Espectrometria de massas (MS)}

A cromatografia é um método físico-químico de separação, no qual os compostos a serem separados são distribuídos entre duas fases, a primeira fase é fixa e possui uma grande área superficial denominada fase estacionária e a segunda é representada pelo gás que percola a primeira fase, sendo, portanto, a fase móvel (NIESSEN, 2001; YUWONO e INDRAYANTO, 2004). 
A cromatografia gasosa (GC) é uma das técnicas de análise cromatográfica com maior poder de resolução, sendo capaz de separar dezenas de compostos em uma mesma análise. Acoplada a variados tipos de detectores, essa técnica pode alcançar baixos limites de quantificação, o que a torna uma ótima técnica quantitativa (PETROVIC et al., 2002; COLLINS et al., 2006).

Um cromatógrafo a gás é basicamente composto pelo gás de arraste, sistema de injeção de amostra, controlador da vazão e regulador de pressão, um forno de temperatura programável onde está localizada a coluna cromatográfica, sistema de detecção e um registrador dos dados (YUWONO e INDRAYANATO, 2004; COLLINS et al., 2006). No GC o analito volátil ou volatilizável, termicamente estável é transportado pelo gás de arraste através de uma coluna, sendo assim, uma fase gasosa móvel. A coluna pode ser do tipo gás-líquido ou gás-sólido, na primeira a fase estacionária é um líquido não volátil que recobre a coluna internamente ou um suporte sólido finamente dividido. Na segunda, o analito é diretamente adsorvido sobre as partículas sólidas da fase estacionária (HARRIS, 2012).

A fase móvel deve ser quimicamente inerte e, sendo assim, o He é a fase móvel mais comum. As colunas capilares e colunas empacotadas são comumente empregados em GC, sendo as capilares mais utilizadas atualmente e possuem geralmente entre 30 e $50 \mathrm{~m}$ de comprimento (SKOOG et al., 2006).

A cromatografia gasosa não consegue qualificar os analitos por si só, sendo necessário o uso de detectores para a qualificação e quantificação dos mesmos. Dentre os detectores utilizados em equipamentos de GC podem-se citar os por ionização em chama (flame ionization detector, FID), por condutividade térmica (thermal conductivity detector, TCD), por captura de elétrons (electron capture detector, ECD) e o detector por espectrometria de massas (mass spectrometry, MS) (COLLINS et al., 2006; HERBERT e JOHNSTONE, 2002).

Skoog et al (2006) afirmam que para um detector ser ideal, é necessário que o mesmo apresente uma boa reprodutibilidade, boa estabilidade e sensibilidade, boa resolução, faixa de temperatura desde a ambiente até $400^{\circ} \mathrm{C}$, tempo de resposta curto e independente da vazão, alta confiabilidade e facilidade de uso, similaridade de resposta a todos os solutos e não pode destruir os analitos de interesse.

A espectrometria de massas é uma técnica microanalítica de grande relevância, por ser capaz de identificar compostos com o mesmo tempo de retenção, além de ser capaz de elucidar a estrutura dos constituintes de uma amostra (VEGA-BUSTILLOS et al., 2001). No GC-MS, a amostra está na forma 
de vapor e a entrada deve ser interfaceada entre a pressão atmosférica do sistema da cromatografia gasosa e a baixa pressão $\left(10^{-5}\right.$ a $\left.10^{-8}\right)$ do sistema do espectrômetro de massas.

No MS, as moléculas entram em uma fonte de ionização. Essas fontes para a espectrometria de massas moleculares são energéticas o suficiente para romper as ligações químicas das moléculas do analito, porém não são suficientes para decompor as moléculas do analito em seus átomos constituintes. No GC-MS as fontes de ionização produzem fragmentos, que podem também ser ionizados. Sendo assim, os íons das moléculas do analito, chamados de íons moleculares, íons de fragmentos e moléculas não-ionizadas, saem da fonte de ionização (SKOOG et al., 2006). A Figura 8 representa o fundamento de um GC-MS.
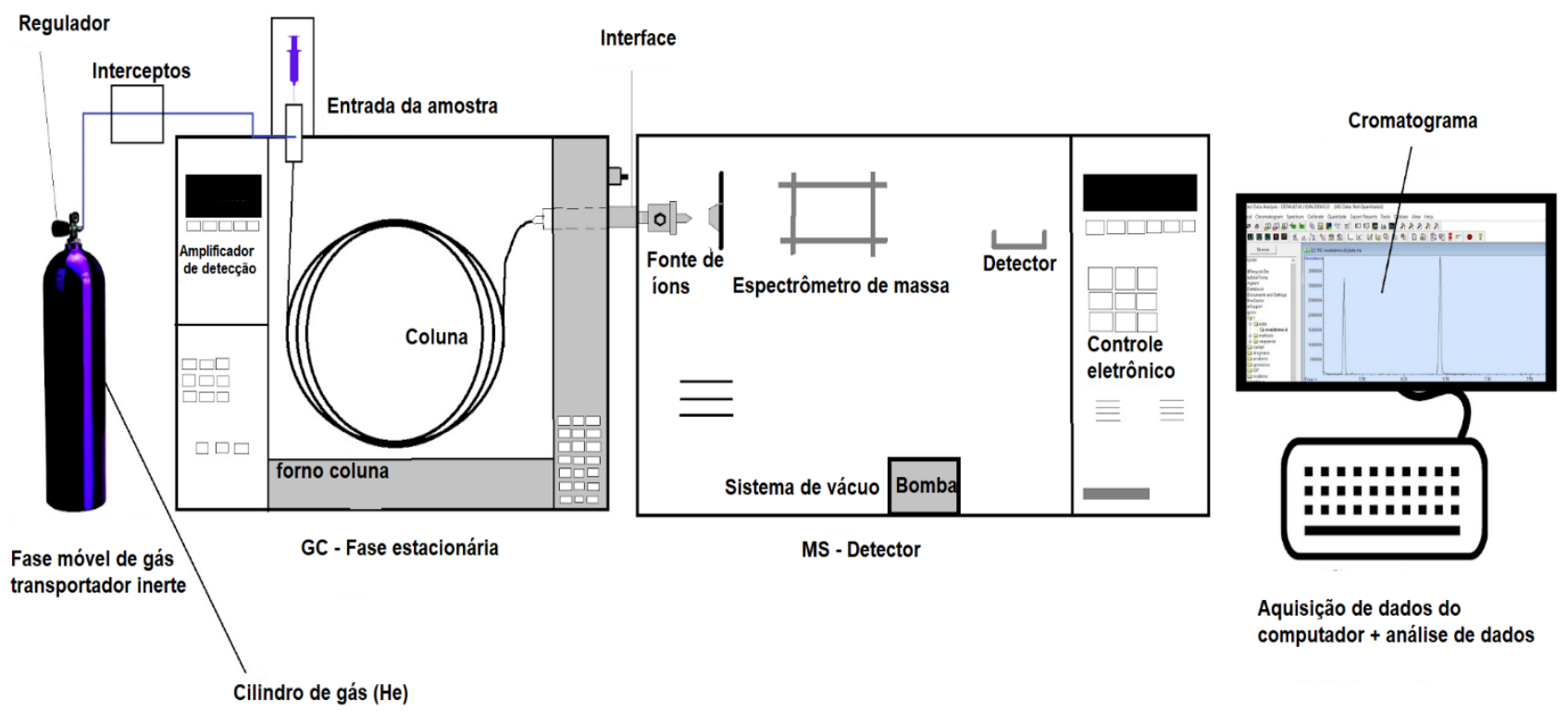

Figura 8 - Esquema de um GC-MS. Adaptado de www.chemwifi.com/2020/12/fundamental-gc-ms.html

\subsection{Validação do método analítico}

Segundo LANÇAS, (2004) a validação é o ato ou efeito de validar, dar validade, tornar ágil, sendo indispensável a realização de mecanismos que confirmem que o método sugerido forneça resultados confiáveis. Portanto, a 
confiabilidade de resultados analíticos através das técnicas cromatográficas é garantida pela validação do método. Com isso, por evidências objetivas, a validação pode ser definida como uma comprovação de que as condições exigidas para tal aplicação foi alcançada (INMETRO, 2011).

No Brasil as agências ANVISA e INMETRO recomenda que os parâmetros avaliados sejam linearidade, sensibilidade, seletividade, limite de detecção, limite de quantificação, precisão e exatidão (VILELA, 2017).

\subsubsection{Linearidade}

Define-se como linearidade o método capaz de mostrar resultados nos intervalos de concentrações pré-estabelecidos de forma linear (ANVISA, 2003). Para o estudo desse parâmetro, a elaboração da curva analítica é importante, tendo em vista que a mesma deve satisfazer uma faixa de 50 a $150 \%$ do valor que é esperado no estudo (RIBANI et al., 2004).

\subsubsection{Sensibilidade}

Esse parâmetro é capaz de especificar concentrações aproximadas de um analito. Através do coeficiente angular da reta é possível determinar a sensibilidade e a partir do valor encontrado pode-se estimar o quão sensível é o método, sendo assim, quanto maior o ângulo de inclinação, mais sensível o método será (LANÇAS, 2004).

\subsubsection{Seletividade}

O método é considerado seletivo, quando o mesmo é capaz de identificar de forma explícita os analitos de outras substâncias, que de alguma forma possam interferir na sua determinação (LANÇAS, 2004). Na maioria dos casos, a maneira mais simples de avaliar a seletividade de um método cromatográfico é verificar a presença de picos na região do tempo de retenção do analito de interesse, comparando a amostra controle da matriz (branco) com o extrato fortificado (LANÇAS, 2004; BRITO et al., 2013). 


\subsubsection{Limite de detecção (LD) e Limite de Quantificação (LQ)}

O limite de detecção refere-se à menor quantidade de um analito que pode ser detectada, mas, não obrigatoriamente quantificada como um valor exato. Por outro lado, o limite de quantificação refere-se à menor quantidade de um analito que pode ser quantificada com exatidão e com determinada fidelidade (LEITE et al., 2008).

\subsubsection{Exatidão}

A exatidão é considerada como sendo o grau de concordância entre os próprios resultados obtidos em um experimento e um valor de referência considerado como verídico. Na exatidão, os processos mais empregados para a avaliação do método são: comparação entre métodos, análise de material de referência e adição de padrão (RIBANI et al., 2004; LEITE et al., 2008).

\subsubsection{Precisão}

A precisão do método consiste da determinação sob condições de repetibilidade ou reprodutibilidade, sendo frequentemente expresso por desvio padrão e coeficiente de variação de uma série de repetições da mesma amostra em diferentes preparações (INMETRO, 2003).

$$
\text { CV }(\%)=\frac{S}{X} X 100 \text { Equação (1) }
$$

Onde X é a média aritmética das determinações e s o desvio padrão entre as determinações. A precisão pode ser avaliada através da repetibilidade (precisão intra-corrida) que verifica a concordância entre os resultados dentro de um curto período de tempo com o mesmo analista e mesma instrumentação.

Como o coeficiente de variação analisa a dispersão em termos relativos, ele será dado em \%. Quanto menor for o valor do coeficiente de variação, mais homogêneos serão os dados, ou seja, menor será a dispersão em torno da média. Quando for menor $15 \%$ é considerado com baixa dispersão, ou seja, dados homogêneos. Já quando está entre $15 \%$ e $30 \%$ é de média dispersão e acima de $30 \%$ é de alta dispersão, dados heterogêneos. 


\section{Materiais e Métodos}

\subsection{Procedimento Experimental}

\subsubsection{Amostras}

Para esse estudo foram utilizadas amostras de mexilhão oriundas de Arraial do Cabo. Essas amostras já haviam sido analisadas por outro método (extração Soxhlet) no LabMAM, ou seja, as amostras já haviam sido trituradas com auxílio de um liquidificador comercial, armazenadas em recipientes de alumínio e estocadas em um ultrafreezer a $-80^{\circ} \mathrm{C}$ para a realização e desenvolvimento do método QuEChERS.

\subsubsection{Higienização dos materiais}

As vidrarias e materiais utilizados no desenvolvimento desse trabalho foram limpos com solução de detergente, lavadas com água corrente e destilada, em seguida levados a estufa para a secagem (exceto vidrarias calibradas), após isso foram retirados e lavados com hexano ou diclorometano grau pesticida. Os materiais tiveram sua extremidade envolvida em papel alumínio e foram armazenados em recipientes com tampa e guardados em seus respectivos armários.

\subsubsection{Descarte dos resíduos}

Os resíduos gerados nesse trabalho foram devidamente descartados em recipientes de vidro para os líquidos e galões de plástico para os sólidos, ambos recipientes foram identificados e alocados em local seguro até o momento da coleta. 


\subsubsection{Padrões analíticos}

Uma solução de HPAs contendo os 16 HPAs prioritários de acordo com a USEPA foi utilizada nesse trabalho, a solução continha naftaleno, acenaftileno, acenafteno, fluoreno, fenantreno, antraceno, fluorantreno, pireno, benzo[a]antraceno, criseno, benzo[b]fluoranteno, Benzo[k]fluoranteno, benzo[a]pireno, indeno[1,2,3-c,d]pireno, dibenzo[a,h]antraceno e benzo[g,h,i]perileno adquirida da Merck em concentração de $100 \mu \mathrm{g} \mathrm{mL}{ }^{-1}$ dissolvidos em diclorometano. Além disso, foi utilizada uma solução de padrões internos deuterados (naftaleno- $D_{8}$, acenafteno- $D_{10}$, fenantreno- $D_{10}$, criseno- $D_{12} \mathrm{e}$ perileno- $\mathrm{D}_{12}$ ), cada um em concentração fixa igual a $100 \mathrm{ng} \mathrm{mL}^{-1}$ ).

\subsubsection{Solventes, adsorventes e sais}

Foram utilizados como solvente, acetona, acetato de etila e isoctano, todos com grau pesticida de pureza. Os adsorventes usados foram o PSA, $\mathrm{C}_{18}, \mathrm{MgSO}_{4}$ e Z-sep+. Já os sais utilizados foram o $\mathrm{NaCl}$ e $\mathrm{MgSO}_{4} . \mathrm{O} \mathrm{C}_{18}$ foi tratado com ultrassom e banho de diclorometano por 30 minutos, foi repetido esse processo 3 vezes. Os sais $\mathrm{NaCl} \mathrm{e} \mathrm{MgSO}_{4}$, foram calcinados por 6 horas na temperatura de $450^{\circ} \mathrm{C}$.

\subsubsection{Equipamentos}

Balança analítica; Centrífuga; Vortex; Mesa agitadora; Mufla; Espectrômetro de Massas - Finnigan, modelo ISQ; Cromatógrafo à gás - Finnigan, modelo TraceGC.

\subsubsection{Parâmetros Cromatográficos}

A análise instrumental para os HPAs seguiu o protocolo EPA-8270D adaptado pelo LabMAM, utilizando cromatografia em fase gasosa acoplada à espectrometria de massas. As condições instrumentais estão listadas na Tabela 3. A calibração do equipamento foi feita com curva de calibração com 12 concentrações $\left(0.5,1,2,5,10,20,50,100,200,400,1000\right.$ e $\left.2000 \mathrm{ng} \mathrm{mL}^{-1}\right)$ de solução contendo os 44 HPAs controlados pelo método, sendo que nesse trabalho apenas serão quantificados os $16 \mathrm{HPAs}$ prioritários (naftaleno, acenaftileno, acenafteno, fluoreno, fenantreno, antraceno, fluoranteno, pireno, 
benzo(a)antraceno, criseno, benzo(b)fluoranteno, benzo(k)fluoranteno, benzo(a)pireno, indeno(1,2,3-c,d)pireno, dibenzo(a,h)antraceno, benzo(ghi)perileno). Em cada solução da curva de calibração havia ainda os padrões internos deuterados (naftaleno- $D_{8}$, acenafteno- $D_{10}$, fenantreno- $D_{10}$, criseno- $D_{12}$ e perileno- $D_{12}$ ), cada um em concentração fixa igual a $100 \mathrm{ng} \mathrm{mL}$ ).

Tabela 2 - Condições instrumentais para determinação de HPAs individuais.

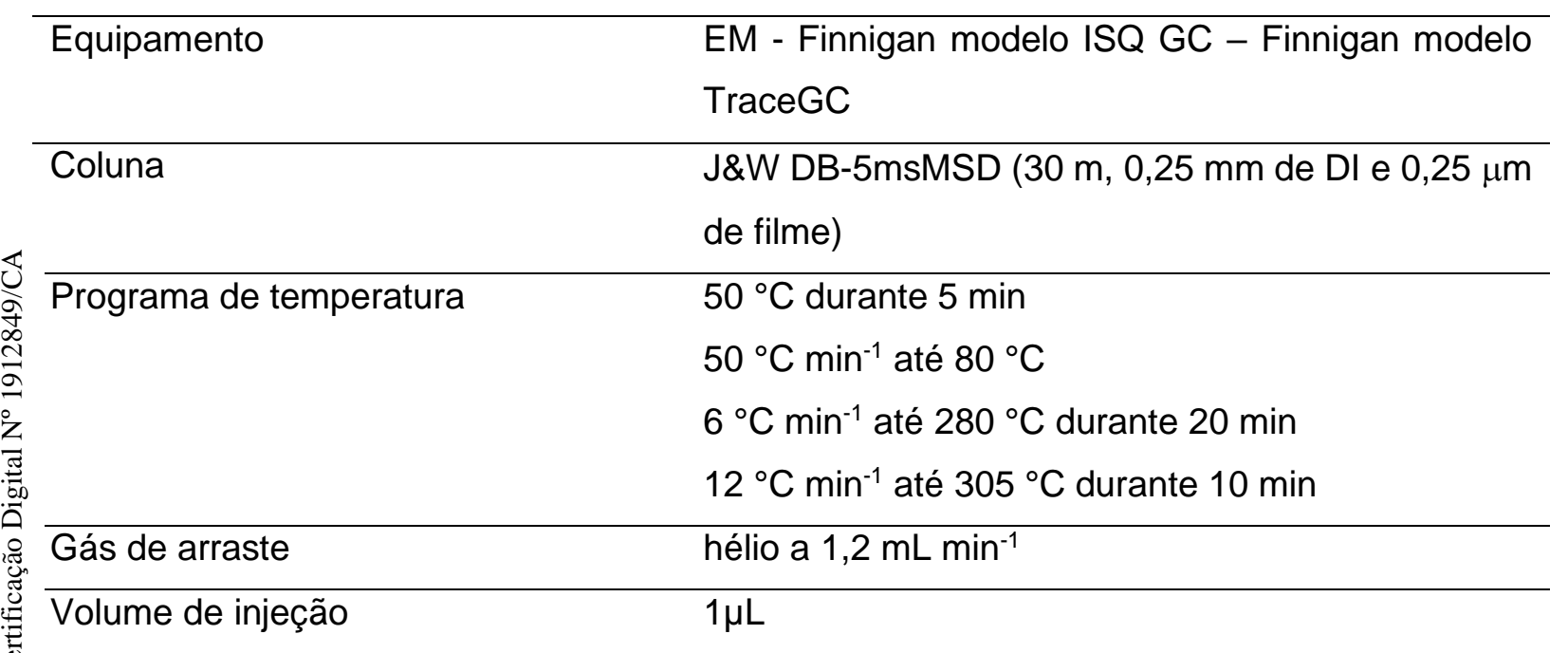

\subsection{Ensaios de Validação}

\subsubsection{Linearidade}

A linearidade foi avaliada por meio de diluições da solução conjunta dos HPAs. Estas diluições resultaram em soluções com concentrações iguais a 1, 2, $5,10,25$ e $50 \mathrm{ng} \mathrm{mL}^{-1}$. A curva analítica foi assegurada por amostras de mexilhão, em triplicatas que foram fortificadas com seis níveis de concentração. Após todo processo de extração e clean-up, foram injetadas e quantificadas através da razão de área de cada um dos analitos pelo padrão interno. 


\subsubsection{Sensibilidade}

A sensibilidade foi avaliada através do coeficiente angular da reta, o qual indica que quanto maior o ângulo de inclinação da reta, mais sensível será o método para o analito. As curvas analíticas para cada um dos compostos foram obtidas com o auxílio do Software Microsoft Excel.

\subsubsection{Seletividade}

A avaliação da seletividade foi feita através de injeções no sistema cromatográfico (GC-MS) do extrato da matriz branco, ou seja, extrato sem os analitos em estudo e de uma amostra fortificada com os analitos. Realizou-se uma comparação entre os espectros de massas do branco e de uma amostra fortificada, a fim de verificar a ocorrência de alguma coeluição entre os analitos e os interferentes da matriz, garantindo a pureza.

\subsubsection{Limite de detecção e limite de quantificação}

Os limites de detecção do método (LD) foram definidos como 3 vezes o desvio padrão da quantificação de 5 replicatas de uma amostra (LD $=3 \times \mathrm{DP})$, o limite de quantificação do método (LQ) foi definido como 3 vezes o LD. (WADE \& CANTILLO, 1994).

\subsubsection{Exatidão}

A exatidão foi avaliada por meio de ensaios com um material de referência certificado NIST - 2974a, seguindo o método de extração por QuEChERS e por ASE.

\subsubsection{Precisão}

A avaliação da precisão pode ser feita por condições de repetibilidade ou em condições de reprodutibilidade. Nesse estudo foi realizado ensaios na condição de repetibilidade, usando a mesma metodologia, na mesma amostra, no mesmo laboratório, pelo mesmo operador, utilizando o mesmo equipamento, sendo os ensaios realizados no mesmo dia (intradia) (LANÇAS, 2004). A precisão foi medida por meio do coeficiente de variação (C.V.) de acordo com a equação (1). Toda marcha analítica foi realizada em triplicata em três níveis de fortificação 
e o coeficiente de variação foi calculado a partir da média e dos desvios padrões dessas determinações.

\subsection{Extração e purificação da amostra empregando QuEChERS}

A extração e a purificação foram adaptadas usando como base as referências de FORSBERG et al., 2011 e JOHNSON, 2012, a Tabela 3 abaixo detalha os parâmetros utilizados por cada autor.

Tabela 3 - Parâmetros usados por Forsberg et al., 2011 e Johnson, 2012 para aplicação do método QuEChERS em biota marinha.

\begin{tabular}{|c|c|c|c|c|c|}
\hline Referência & $\begin{array}{c}\text { Massa de } \\
\text { amostra (g) }\end{array}$ & $\begin{array}{c}\text { Volume de } \mathrm{H}_{2} \mathrm{O} \text { e } \\
\text { solvente de extração } \\
(\mathrm{mL})\end{array}$ & $\begin{array}{c}\text { Sais de } \\
\text { extração (g) }\end{array}$ & Sais d-SPE (g) & Matriz \\
\hline 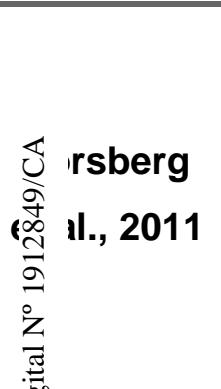 & $1 \mathrm{~g}$ & $\begin{array}{c}1 \mathrm{~mL} \text { de } \mathrm{H}_{2} \mathrm{O} / 2 \mathrm{~mL} \text { de } \\
\text { acetona, acetato de } \\
\text { etila e isooctano (2:2:1) }\end{array}$ & $\begin{array}{c}1,3 \mathrm{~g} \text { de sais } \\
\mathrm{AOAC}(6 \mathrm{~g} \\
\text { de } \mathrm{MgSO}_{4}+ \\
1,5 \mathrm{~g} \text { de } \\
\text { acetato de } \\
\text { sódio) }\end{array}$ & $\begin{array}{c}250 \mathrm{mg} \text { de sais } \\
\text { AOAC (50 mg de } \\
\mathrm{C}_{18}+50 \mathrm{mg} \text { de } \\
\mathrm{PSA}+150 \mathrm{mg} \text { de } \\
\left.\mathrm{MgSO}_{4}\right)\end{array}$ & Salmão \\
\hline 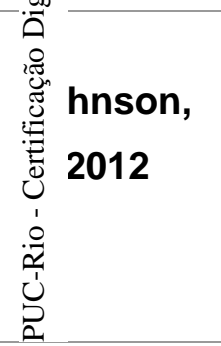 & $5 \mathrm{~g}$ & $\begin{array}{c}5 \mathrm{~mL} \text { de } \mathrm{H}_{2} \mathrm{O} / 10 \mathrm{~mL} \text { de } \\
\mathrm{MeCN}\end{array}$ & $\begin{array}{l}4 \quad \mathrm{~g} \text { de } \\
\mathrm{MgSO}_{4} \\
\text { anidro }+1 \mathrm{~g} \\
\text { de } \mathrm{NaCl}\end{array}$ & $\begin{array}{c}150 \mathrm{mg} \text { de } \mathrm{C}_{18}+ \\
150 \mathrm{mg} \text { de } \mathrm{PSA}+ \\
900 \mathrm{mg} \text { de } \mathrm{MgSO}_{4}\end{array}$ & $\begin{array}{c}\text { Caranguejo, } \\
\text { ostras, } \\
\text { camarão e } \\
\text { peixe }\end{array}$ \\
\hline
\end{tabular}

Em condições otimizadas, as análises foram definidas da seguinte forma: 2,0 $\mathrm{g}$ da amostra foram pesados em um tubo de teflon e logo após adicionaramse $20 \mu \mathrm{L}$ da solução de HPAs (5 $\mathrm{ng} \mathrm{LL}^{-1}$ ) e/ou adicionaram-se $100 \mathrm{ng}$ de padrão interno (naftaleno- $D_{8}$, acenafteno- $D_{10}$, fenantreno- $D_{10}$, criseno- $D_{12}$ e perileno- $D_{12}$ ), permanecendo em repouso por 30 minutos para a evaporação do solvente e interação dos analitos com a matriz. Posteriormente, foram adicionados $2 \mathrm{~mL}$ de $\mathrm{H}_{2} \mathrm{O}$ e agitou-se por 1 minuto com auxílio da mesa agitadora com rotação de 200 RPM. Em seguida, $4 \mathrm{~mL}$ de uma solução de solvente contendo acetona, acetato de etila e isoctano na proporção 2:2:1 foram adicionados, e a mistura agitada por 5 minutos. Logo após, adicionaram-se $2,0 \mathrm{~g}$ de sais AOAC $\left(1,6 \mathrm{~g}\right.$ de $\mathrm{MgSO}_{4}$ e 0,4 de $\mathrm{NaCl}$ ), que tem como função realizar a partição da fase orgânica e líquida da 
amostra, agitou-se por mais 5 minutos com rotação de 200 RPM e, posteriormente, centrifugado por 5 minutos com rotação de 6000 RPM.

A etapa de purificação consiste na retirada da fase orgânica da etapa de extração observada após centrifugação, que em seguida é transferida para um tubo contendo sais d-SPE AOAC (100 mg de PSA $+100 \mathrm{mg}$ de $\mathrm{C}_{18}+300 \mathrm{mg}$ de $\mathrm{MgSO}_{4}$ ) e agitada por 5 minutos na mesa agitadora, posteriormente por mais 5 minutos na centrífuga com rotação de 6000 RPM. No final dessa etapa de purificação, todo o extrato é transferido para um vial e reduzido seu volume com $\mathrm{N}_{2}$ até o volume final de $500 \mu \mathrm{L}$ com a adição de $100 \mathrm{ng}$ de p-terfenil $\mathrm{D}_{14}$ (surrogate). Esse vial é direcionado para análise em GC-MS. A Figura 9 abaixo demonstra um fluxograma do protocolo estabelecido para as análises. 


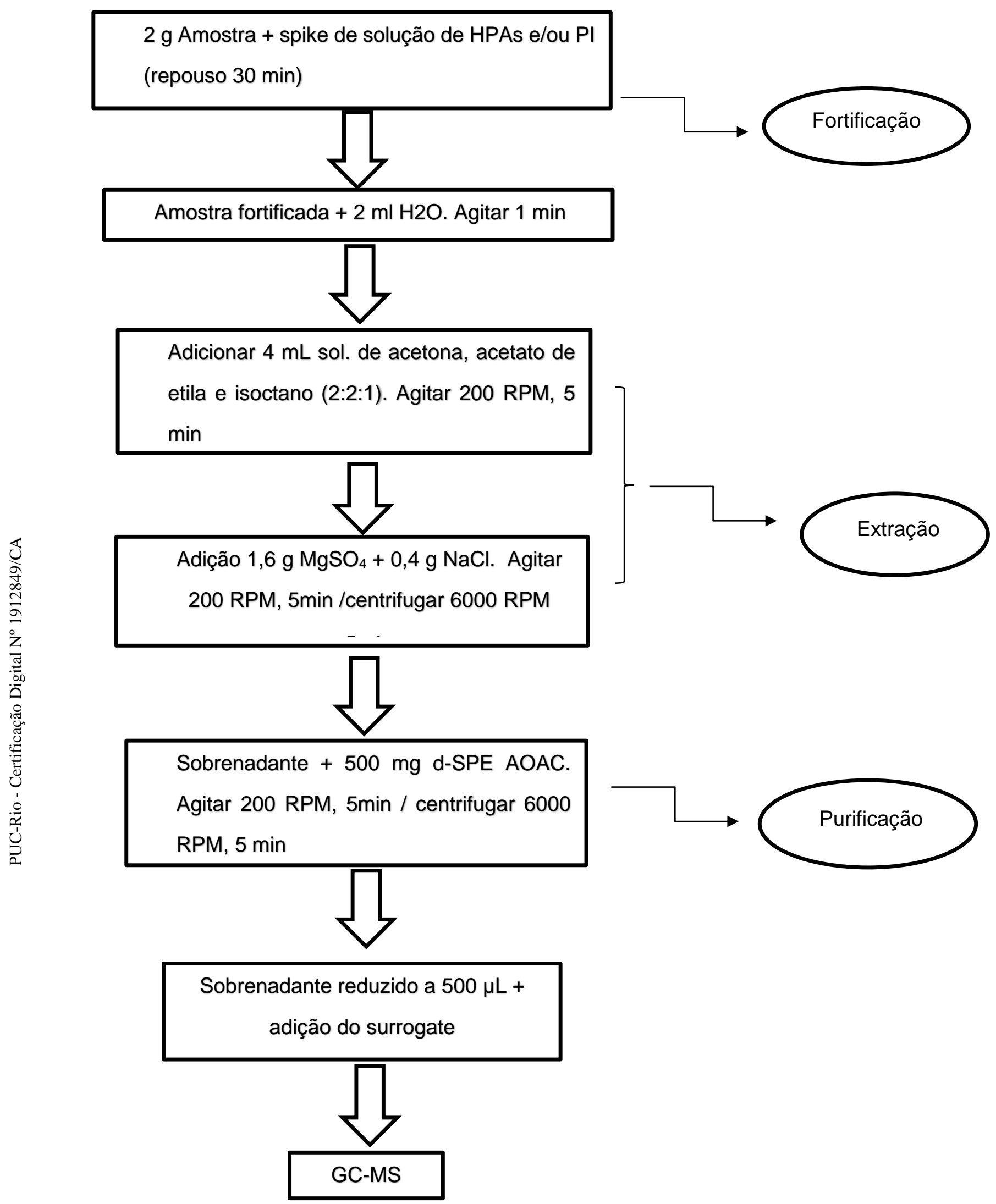

Figura 9 - Fluxograma para determinar HPAs em biota usando QuEChERS.

(Adaptado de FORSBERG et al., 2011 e JOHNSON, 2012) 


\subsection{Otimização da Purificação}

Nesse trabalho, foram realizados experimentos com a finalidade de estimar a influência da etapa de purificação para a identificação dos analitos. Essa otimização foi realizada depois que o GC-MS precisou de manutenções para limpeza do injetor e das fontes devido à possível presença de gordura residual nos extratos, que causaram danos ao equipamento e fazendo com que houvessem manutenções constantes. Para isso, foram realizados 5 testes para melhorar deixar o extrato mais puro.

O procedimento de extração foi realizado conforme descrito no item 3.3, porém a etapa de purificação sofreu algumas alterações, pois a matriz escolhida para o estudo apresenta alto teor lipídico. Assim, para eliminar os possíveis interferentes do extrato, foram realizados os seguintes testes, de acordo com a Tabela 5. Todas as análises foram fortificadas com $50 \mathrm{ng}$ de uma solução contendo os 16 HPAs prioritários, para calcular posteriormente a recuperação que cada teste proporciona.

Tabela 4 - Testes de otimização da purificação do método QuEChERS.

\begin{tabular}{|c|c|}
\hline Teste & Purificação \\
\hline 1 & $\begin{array}{c}100 \mathrm{mg} \text { de } \mathrm{PSA}+100 \mathrm{mg} \text { de } \mathrm{C}_{18}+300 \\
\mathrm{mg} \text { de } \mathrm{MgSO}_{4}\end{array}$ \\
\hline 2 & $\begin{array}{c}200 \mathrm{mg} \text { de } \mathrm{PSA}+200 \mathrm{mg} \text { de } \mathrm{C}_{18}+600 \\
\mathrm{mg} \text { de } \mathrm{MgSO}_{4}\end{array}$ \\
\hline 3 & $\begin{array}{c}100 \mathrm{mg} \text { de } \mathrm{PSA}_{+} 100 \mathrm{mg} \text { de } \mathrm{C}_{18}+300 \\
\mathrm{mg} \text { de } \mathrm{MgSO}_{4}+\text { Coluna de Alumina }\end{array}$ \\
\hline 4 & 500 mg Z-Sep ${ }^{+}$ \\
\hline 5 & $\begin{array}{c}500 \text { mg Z-sep }+ \text { + Coluna de Sílica e } \\
\text { Alumina }\end{array}$ \\
\hline
\end{tabular}

Para a realização do teste 3 , o extrato seguiu a mesma etapa de purificação do teste 1 e após isso, o extrato passou por uma coluna com 0,5 g de alumina $5 \%$ em uma pipeta Pasteur e adicionaram-se aos poucos cerca de $2 \mathrm{~mL}$ de uma mistura de diclorometano e hexano $(1: 1 \mathrm{v} / \mathrm{v})$ para eluição. $\mathrm{O}$ extrato final foi concentrado a $1 \mu \mathrm{L}$ utilizando um concentrador de nitrogênio. $O$ teste 5 foi 
realizado nas mesmas condições do teste 4 , porém com a adição de uma coluna de sílica ( $8 \mathrm{~g}$ e desativada em 5\%) e alumina ( $16 \mathrm{~g}$, desativada em 5\%), e eluição de $20 \mathrm{~mL}$ de uma mistura de diclorometano e hexano $(1: 1 \mathrm{v} / \mathrm{v})$, e redução do extrato a, $1 \mu \mathrm{L}$. A sílica é descontaminada através de refluxo em Soxhlet com diclorometano grau pesticida por no mínimo $6 \mathrm{~h}$ e ativada em estufa à $120^{\circ} \mathrm{C}$, por outro lado a alumina é descontaminada através de combustão em mufla por no mínimo $4 \mathrm{~h}$ à $450^{\circ} \mathrm{C}$. 


\section{Resultados e Discussão}

\subsection{Linearidade}

A linearidade das curvas analíticas foi verificada utilizando-se injeções de soluções padrão preparadas em extrato da amostra (acetona, acetato de etila e isoctano 2:2:1 v/v), nas concentrações $1,2,5,10,25$ e $50 \mathrm{ng} \mathrm{mL}^{-1}$. As curvas foram preparadas e injetadas no sistema, a partir dos resultados obtidos foi possível calcular a média da área de cada analito, obtendo-se sequencialmente a regressão linear e o coeficiente de correlação $(r)$ a fim de determinar a linearidade do método para cada analito.

A Tabela 6 apresenta a curva de analítica para cada HPA analisado e seus respectivos coeficientes de correlação $(r)$.

Tabela 5 - Resultados obtidos para as curvas analíticas e coeficiente de correlação.

\begin{tabular}{|c|c|c|}
\hline Analitos & Curva analítica & r \\
\hline $\mathrm{N}$ & $\mathrm{y}=5,418 \mathrm{x}+85,41$ & 0,981 \\
\hline Aceft & $\mathrm{y}=5,532 \mathrm{x}+0,768$ & 0,999 \\
\hline Ace & $\mathrm{y}=6,289 x-0,772$ & 0,998 \\
\hline Flu & $\mathrm{y}=5,386 \mathrm{x}+7,063$ & 0,999 \\
\hline Fen & $\mathrm{y}=1,972 \mathrm{x}+21$ & 0,980 \\
\hline Ant & $\mathrm{y}=2,308 \mathrm{x}+4,567$ & 0,981 \\
\hline $\mathrm{Ft}$ & $\mathrm{y}=1,964 \mathrm{x}+27,82$ & 0,990 \\
\hline $\mathrm{Pi}$ & $\mathrm{y}=4,533 \mathrm{x}+16,91$ & 0,987 \\
\hline $\mathrm{BaA}$ & $\mathrm{y}=2,971 \mathrm{x}+2,152$ & 0,986 \\
\hline $\mathrm{Cri}$ & $\mathrm{y}=1,587 \mathrm{x}-1,32$ & 0,998 \\
\hline $\mathrm{BbFt}$ & $\mathrm{y}=5,637 \mathrm{x}-3,41$ & 0,998 \\
\hline $\mathrm{BkFt}$ & $\mathrm{y}=3,950 \mathrm{x}+2,078$ & 0,998 \\
\hline $\mathrm{BePi}$ & $\mathrm{y}=5,062 \mathrm{x}+19,54$ & 0,997 \\
\hline $\mathrm{BaPi}$ & $\mathrm{y}=5,521 \mathrm{x}+100,2$ & 0,990 \\
\hline $\mathrm{I}-\mathrm{Pi}$ & $\mathrm{y}=5,242 \mathrm{x}+1,77$ & 0,992 \\
\hline $\mathrm{DbahA}$ & $\mathrm{y}=7,302 \mathrm{x}+31,10$ & 0,999 \\
\hline $\mathrm{BghiPe}$ & $\mathrm{y}=6,13 \mathrm{x}+15,83$ & 0,995 \\
\hline
\end{tabular}

Legenda: N: Naftaleno; Ace: Acenafteno; Aceft: Acenaftileno; Flu: Fluoreno; Fen: Fenantreno; Ant: Antraceno; Ft: Fluoranteno; Pi: Pireno; BaA: Benzo(a)antraceno; Cri: Criseno; BbFt: Benzo(b)fluoranteno; BkFt: 
benzo(k)fluoranteno; BaPi: Benzo(a)pireno; BePi: Benzo(e)pireno; I-Pi: Indeno(1,2,3-cd)pireno; DbahA: Dibenzo(a,h)antraceno; BghiPe: Benzo(ghi)perileno.

A partir dos dados alcançados para o levantamento das curvas analíticas, é possível concluir que a regressão linear é adequada para as determinações analíticas nesse estudo. Os coeficientes de correlação $(r)$ alcançaram valores acima de 0,98, tornando o parâmetro de linearidade aceitável de acordo com as orientações da ANVISA e do INMETRO, que aceitam $r$ igual a 0,99 e acima de 0,90 , respectivamente.

\subsection{Sensibilidade}

Através das curvas analíticas obtidas no ensaio de linearidade, a sensibilidade do método foi representada pelo coeficiente angular da reta. Sendo, assim, o dibenzo(a,h)antraceno, apresentou a maior sensibilidade do método com o coeficiente angular igual a 7,302, e o composto com menor sensibilidade foi o criseno, com coeficiente angular igual a 1,587.

\subsection{Seletividade}

A seletividade foi avaliada através dos espectros de massa obtidos pelo GCMS e pela escolha de um determinado tempo de retenção (10,89-26,97 minutos) para essa avaliação. A partir do espectro de massa da solução de HPAs de $50 \mathrm{ng}$ em comparação ao espectro de massa do solvente (hexano) foi possível avaliar a seletividade do método, como se observa na Figura 10 (branco) e Figura 11 (espectro de solução padrão contendo HPAs). Pode-se observar que dentro do tempo de retenção analisado, os picos em 25,37 e 25,59 são correspondentes ao fenantreno e antraceno. 


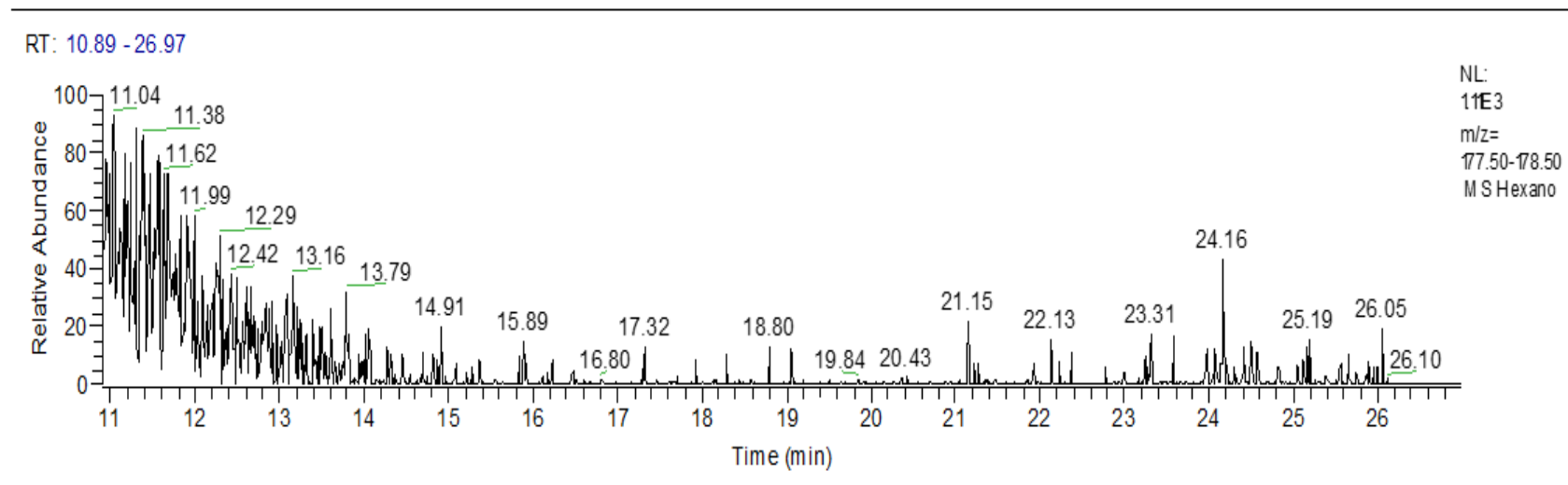

Figura 10 - Espectro de massa (full scan) do solvente (branco) obtido pelo GCMS.

Solução de HPAs

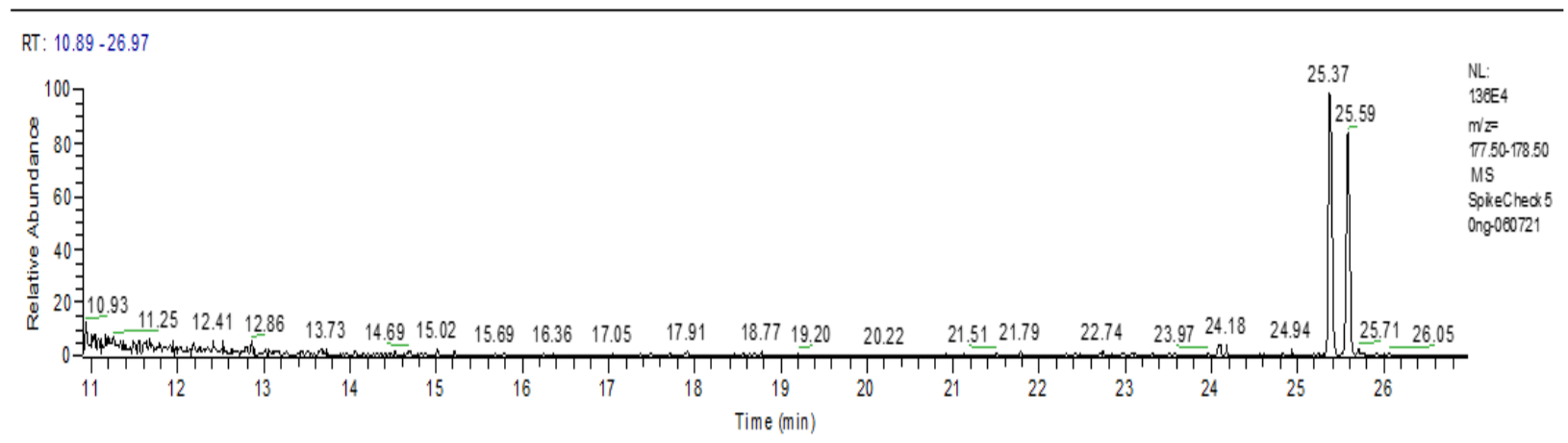

Figura 11 - Espectro de massa da solução de HPAs 50 ng obtido pelo GC-MS do fenantreno e antraceno.

\subsection{Limite de detecção e limite de quantificação}

Os limites de detecção (LD) e quantificação (LQ) foram determinados através do desvio padrão da quantificação dos HPAs das replicatas da amostra, onde o $L D=3 \times$ DP e o LQ $=3 \times L D$. Os valores de LD e LQ encontrados para cada HPA estão descritos na Tabela 7. Os valores de LD encontrados estão entre 0,377 e 7,45 $\mathrm{ng} \mathrm{g}^{-1}$. Enquanto que, os LQ apresentaram variação de 1,13 a 22,36 ng $\mathrm{g}^{-1}$. 
Tabela 6 - Limite de Detecção e de Quantificação do Método, considerando a massa de amostra de $2,0 \mathrm{~g}$.

\begin{tabular}{|c|c|c|}
\hline HPA & LD $\left(\mathbf{n g ~ ~ ^ { - 1 }}\right)$ & LQ $\mathbf{~} \mathbf{~}_{\mathbf{~ g}}^{\mathbf{- 1}} \mathbf{)}$ \\
\hline $\mathbf{N}$ & 2,98 & 8,94 \\
\hline Aceft & 1,93 & 5,81 \\
\hline Ace & 0,823 & 2,46 \\
\hline Flu & 0,937 & 2,81 \\
\hline Fen & 1,68 & 5,06 \\
\hline Ant & 2,01 & 6,04 \\
\hline Ft & 0,544 & 1,63 \\
\hline $\mathrm{Pi}$ & 4,03 & 12,09 \\
\hline $\mathrm{BaA}$ & 2,45 & 7,36 \\
\hline $\mathrm{Cri}$ & 0,377 & 1,13 \\
\hline $\mathrm{BbFt}$ & 7,45 & 22,36 \\
\hline $\mathrm{BkFt}$ & 1,57 & 4,72 \\
\hline $\mathrm{BePi}$ & 1,21 & 3,65 \\
\hline $\mathrm{BaPi}$ & 5,06 & 15,20 \\
\hline $\mathrm{I}-\mathrm{Pi}$ & 0,555 & 1,66 \\
\hline $\mathrm{DbahA}$ & 1,31 & 3,93 \\
\hline $\mathrm{BghiPe}$ & 0,871 & 2,61 \\
\hline
\end{tabular}

Legenda: N: Naftaleno; Ace: Acenafteno; Aceft: Acenaftileno; Flu: Fluoreno; Fen: Fenantreno; Ant: Antraceno; Ft: Fluoranteno; Pi: Pireno; BaA: Benzo(a)antraceno; Cri: Criseno; BbFt: Benzo(b)fluoranteno; BkFt: benzo(k)fluoranteno; BaPi: Benzo(a)pireno; BePi: Benzo(e)pireno; I-Pi: Indeno(1,2,3-cd)pireno; DbahA: Dibenzo(a,h)antraceno; BghiPe: Benzo(ghi)perileno.

\subsection{Exatidão}

Para assegurar a exatidão do método, o material de referência NIST - 2974a foi utilizado. A Tabela 8 a seguir apresenta os resultados obtidos da quantificação dos analitos pelo método QuEChERS e pelo ASE no NIST - 2974a e seus respectivos valores de referência. O Figura 12 representa um gráfico que nos permite avaliar a recuperação dos analitos extraídos pelo método QuEChERS em comparação ao material de referência, onde pode-se observar que o Benzo(b)fluoranteno, apresenta a maior recuperação diante os outros analitos. 
Tabela 7 - Resultados da quantificação do material de referência NIST 2974a usando o método QuEChERS.

\begin{tabular}{|c|c|c|c|}
\hline HPA & QuEChERS ng g ${ }^{-1}$ & ASE $\mathbf{n g ~ g}^{-1}$ & Referência $\mathbf{n g ~ g}^{-1}$ \\
\hline $\mathrm{N}$ & ND & ND & $9,7 \pm 0,67$ \\
\hline Fen & 98,0 & 90,0 & $74,4 \pm 4,7$ \\
\hline Ant & ND & 6,8 & $2,5 \pm 0,10$ \\
\hline $\mathrm{Ft}$ & ND & 296,0 & $287,0 \pm 34$ \\
\hline $\mathrm{Pi}$ & 132,0 & 136,0 & $166,0 \pm 21$ \\
\hline $\mathrm{BaA}$ & 26,0 & 48,0 & $31,1 \pm 0,17$ \\
\hline Cri & 108,0 & 158,0 & $85,1 \pm 1,1$ \\
\hline $\mathrm{BbFt}$ & 40,0 & 50,0 & $41,5 \pm 2,6$ \\
\hline $\mathrm{BkFt}$ & 24,0 & 30,0 & $20,0 \pm 0,54$ \\
\hline $\mathrm{BaPi}$ & 12,0 & 10,0 & $9,7 \pm 0,43$ \\
\hline I-Pi & 8,0 & 22,8 & $14,9 \pm 4,5$ \\
\hline BghiPe & 22,8 & 45,2 & $23,7 \pm 2,2$ \\
\hline
\end{tabular}

Legenda: N: Naftaleno; Ace: Acenafteno; Aceft: Acenaftileno; Flu: Fluoreno; Fen: Fenantreno; Ant: Antraceno; Ft: Fluoranteno; Pi: Pireno; BaA: Benzo(a)antraceno; Cri: Criseno; BbFt: Benzo(b)fluoranteno; BkFt: benzo(k)fluoranteno; BaPi: Benzo(a)pireno; BePi: Benzo(e)pireno; I-Pi: Indeno(1,2,3-cd)pireno; DbahA: Dibenzo(a,h)antraceno; BghiPe: Benzo(ghi)perileno; ND: não determinado.

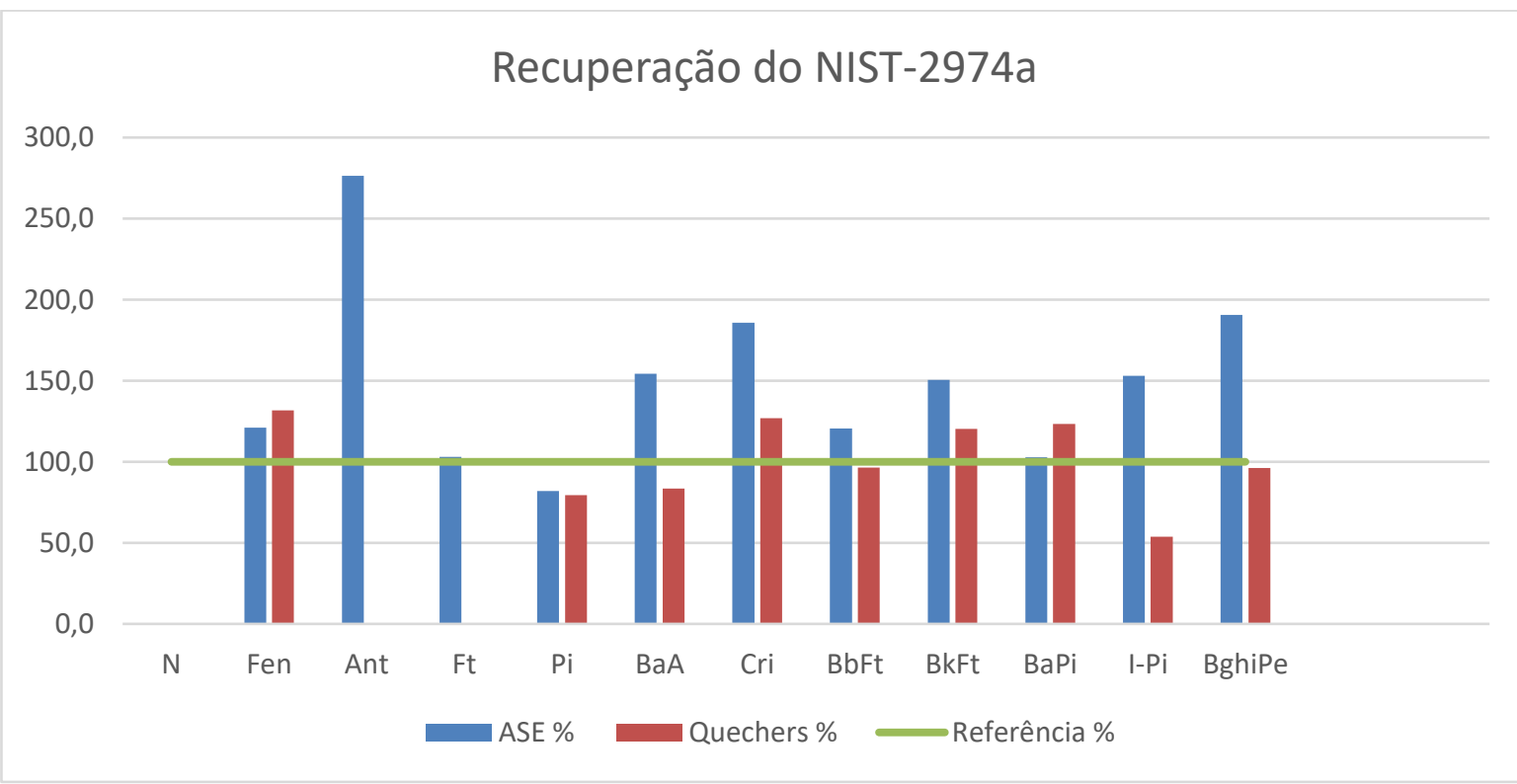

Figura 12 - Recuperação do material de referência a partir do método QUEChERS e ASE.

Nos testes realizados para esse parâmetro, apenas 12 dos 16 HPAs prioritários foram avaliados, pois o material de referência NIST-2974a só contém 
12 dos HPAs de interesse para esse estudo. O antraceno e o fluoranteno pelo método QuEChERS apresentaram alguns interferentes em seus picos, dificultando a quantificação dos mesmos. Para isso geralmente é adicionado uma etapa extra de purificação, que melhoram as condições dos extratos para serem injetados no cromatógrafo, resultando em um extrato com ausência de contaminantes, uma vez que a amostra de trabalho é bastante rica em lipídeos. A recuperação do naftaleno não foi alcançada em ambos os métodos, o padrão interno foi perdido durante o processo, isso pode estar relacionado a perdas durante as etapas de extração e purificação do método, por ser o mais leve em relação aos outros HPAs.

\subsection{Precisão}

A precisão foi avaliada por meio da análise em triplicata de amostra de mexilhão fortificadas com a solução mista de HPAs nos níveis de concentrações de 1, 2 e $5 \mathrm{ng} \mathrm{mL}$, usando o mesmo método, a mesma amostra, no mesmo

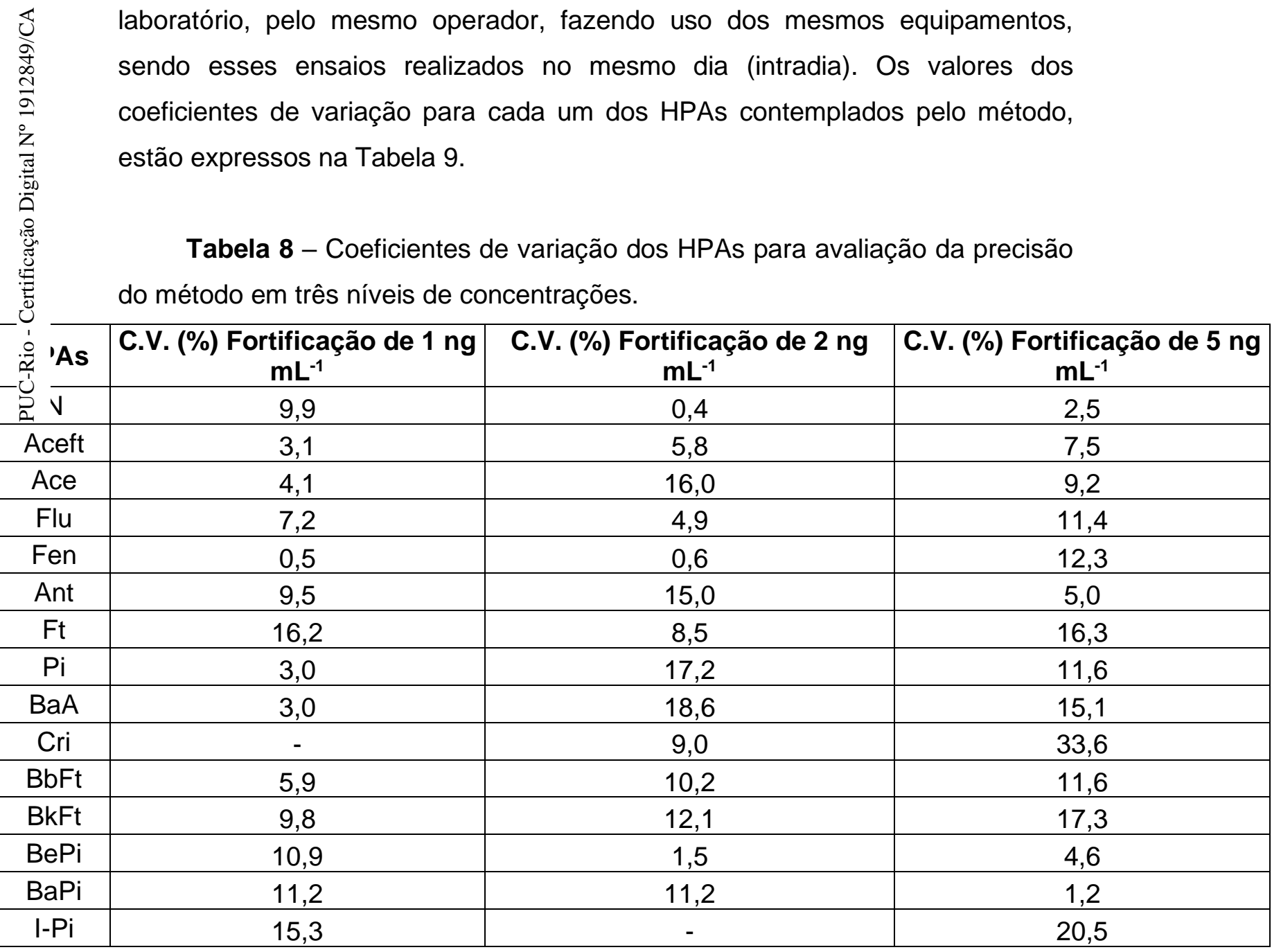




\begin{tabular}{|c|c|c|c|} 
DbahA & 4,0 & 3,0 & 8,6 \\
\hline BghiPe & 10,8 & 13,4 & 8,9 \\
\hline
\end{tabular}

Legenda: N: Naftaleno; Ace: Acenafteno; Aceft: Acenaftileno; Flu: Fluoreno; Fen: Fenantreno; Ant: Antraceno; Ft: Fluoranteno; Pi: Pireno; BaA: Benzo(a)antraceno; Cri: Criseno; BbFt: Benzo(b)fluoranteno; BkFt: benzo(k)fluoranteno; BaPi: Benzo(a)pireno; BePi: Benzo(e)pireno; I-Pi: Indeno(1,2,3-cd)pireno; DbahA: Dibenzo(a,h)antraceno; BghiPe: Benzo(ghi)perileno.

Os resultados para a precisão do método foram bons, apresentando coeficientes de variação entre 0,5 e 33,6\%. O criseno e o indeno(1,2,3-cd)pireno nas réplicas fortificadas com 1 e $2 \mathrm{ng} \mathrm{mL}^{-1}$, estavam abaixo do LD, impossibilitando o cálculo do coeficiente de variação. Todos os HPAs apresentaram coeficiente de variação aceitável, apresentando dados mais homogêneos, exceto o criseno na fortificação de $5 \mathrm{ng} \mathrm{mL}^{-1}$, com 33,6\%.

\subsection{Resultados dos testes de otimização da purificação}

A partir dos testes em triplicatas realizados, foi possível observar as seguintes recuperações para cada HPA analisado, que foram calculadas a partir da média das quantificações dos testes pela fortificação de $50 \mathrm{ng}$. Com base na Tabela 10 e no gráfico da Figura 13 abaixo, conclui-se que o teste 5 apresentou melhores recuperações para alguns HPAs, provando que quanto mais limpo for o extrato, melhores são as condições para a quantificação dos analitos, pois o resultado disso fornece um extrato com a ausência de interferentes. 
Tabela 9 - Percentuais das recuperações dos testes de otimização da purificação.

\begin{tabular}{|c|c|c|c|c|c|}
\hline HPAs & TESTE 1 & TESTE 2 & TESTE 3 & TESTE 4 & TESTE 5 \\
\hline $\mathrm{N}$ & 79,80 & 185,09 & 88,92 & 70,55 & 121,28 \\
\hline Aceft & 59,56 & 76,96 & 52,84 & 56,36 & 56,12 \\
\hline Ace & 108,25 & 178,20 & 84,80 & 73,63 & 75,48 \\
\hline Flu & 72,55 & 102,37 & 68,60 & 55,25 & 105,56 \\
\hline Fen & 103,32 & 59,61 & 107,77 & 78,25 & 79,49 \\
\hline Ant & 55,87 & 59,61 & 47,01 & 43,61 & 62,05 \\
\hline $\mathrm{Ft}$ & 76,48 & 47,12 & 92,63 & 43,01 & 64,96 \\
\hline $\mathrm{Pi}$ & 96,61 & 64,33 & 162,53 & 65,88 & 74,29 \\
\hline $\mathrm{BaA}$ & 107,16 & 51,43 & 47,52 & 73,21 & 53,90 \\
\hline Cri & 33,80 & 48,07 & 44,82 & 45,02 & 55,48 \\
\hline $\mathrm{BbFt}$ & 51,70 & 49,62 & 62,63 & 61,84 & 83,43 \\
\hline $\mathrm{BkFt}$ & 63,62 & 82,74 & 56,59 & 53,21 & 101,41 \\
\hline $\mathrm{BePi}$ & 74,72 & 75,18 & 70,05 & 67,81 & 130,40 \\
\hline $\mathrm{BaPi}$ & 89,83 & 51,22 & 94,40 & 62,72 & 120,62 \\
\hline $\mathrm{I}-\mathrm{Pi}$ & 42,42 & 42,40 & 46,36 & 38,72 & 78,47 \\
\hline DBahA & 51,40 & 49,89 & 44,51 & 50,50 & 89,22 \\
\hline BghiPe & 40,45 & 38,55 & 45,75 & 37,05 & 40,93 \\
\hline
\end{tabular}

Legenda: N: Naftaleno; Ace: Acenafteno; Aceft: Acenaftileno; Flu: Fluoreno; Fen: Fenantreno; Ant: Antraceno; Ft: Fluoranteno; Pi: Pireno; BaA: Benzo(a)antraceno; Cri: Criseno; BbFt: Benzo(b)fluoranteno; BkFt: benzo(k)fluoranteno; BaPi: Benzo(a)pireno; BePi: Benzo(e)pireno; I-Pi: Indeno(1,2,3-cd)pireno; DbahA: Dibenzo(a,h)antraceno; BghiPe: Benzo(ghi)perileno. 


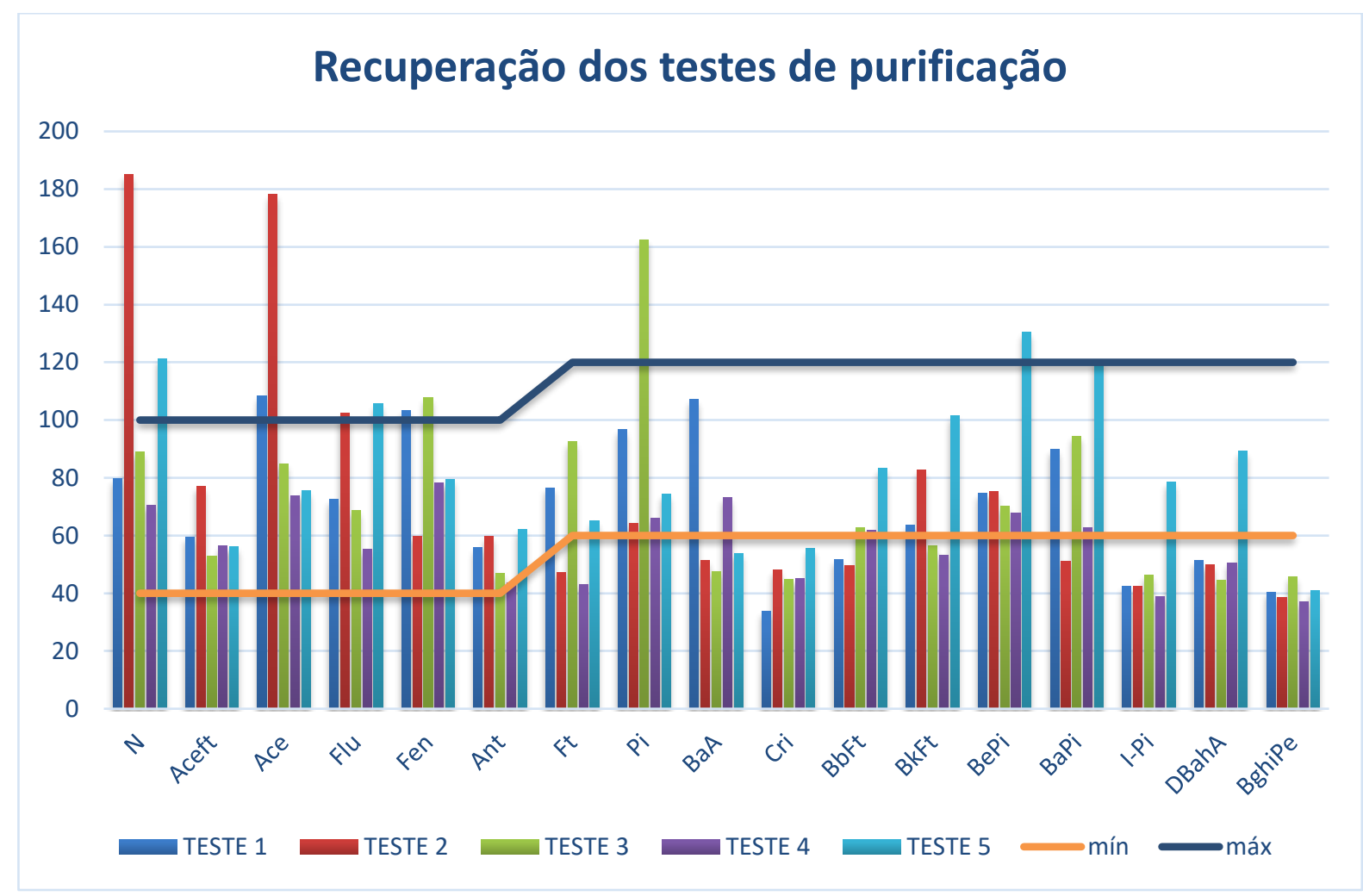

Figura 13 - Recuperação dos testes de otimização da purificação do método QuEChERS.

Para garantir o melhor teste de otimização da purificação das amostras, uma das maneiras de avaliar se existe a presença de interferentes que coeluem com os analitos de interesse é através dos espectros de massa. Escolheu-se os espectros de massa dos testes em um determinado tempo de retenção para serem avaliados. Abaixo seguem os espectros dos testes de otimização da purificação do método QuEChERS. 
TESTE 1

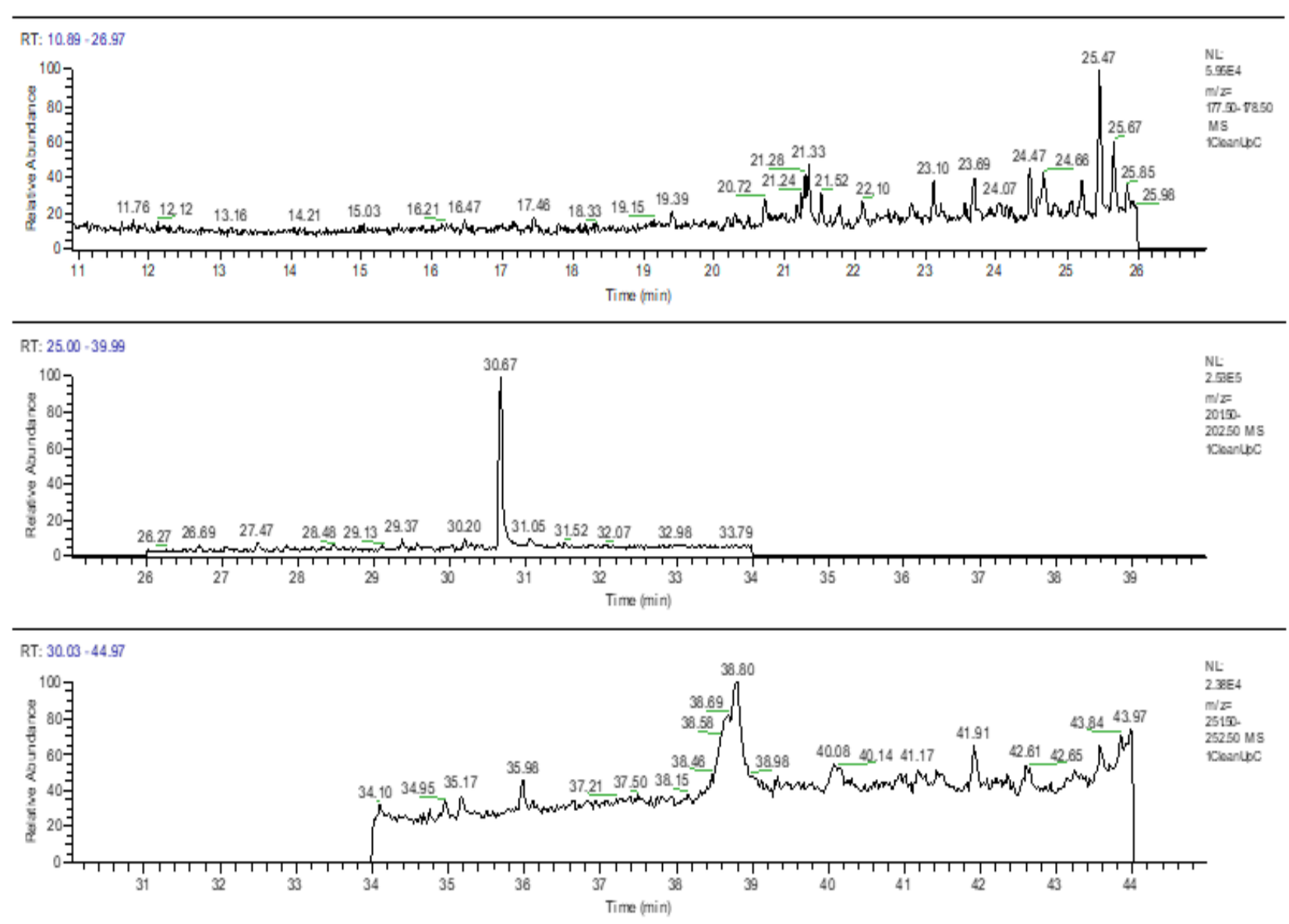

Figura 14 -Espectro de massa do Teste 1 obtido pelo GC-MS. 
TESTE 2

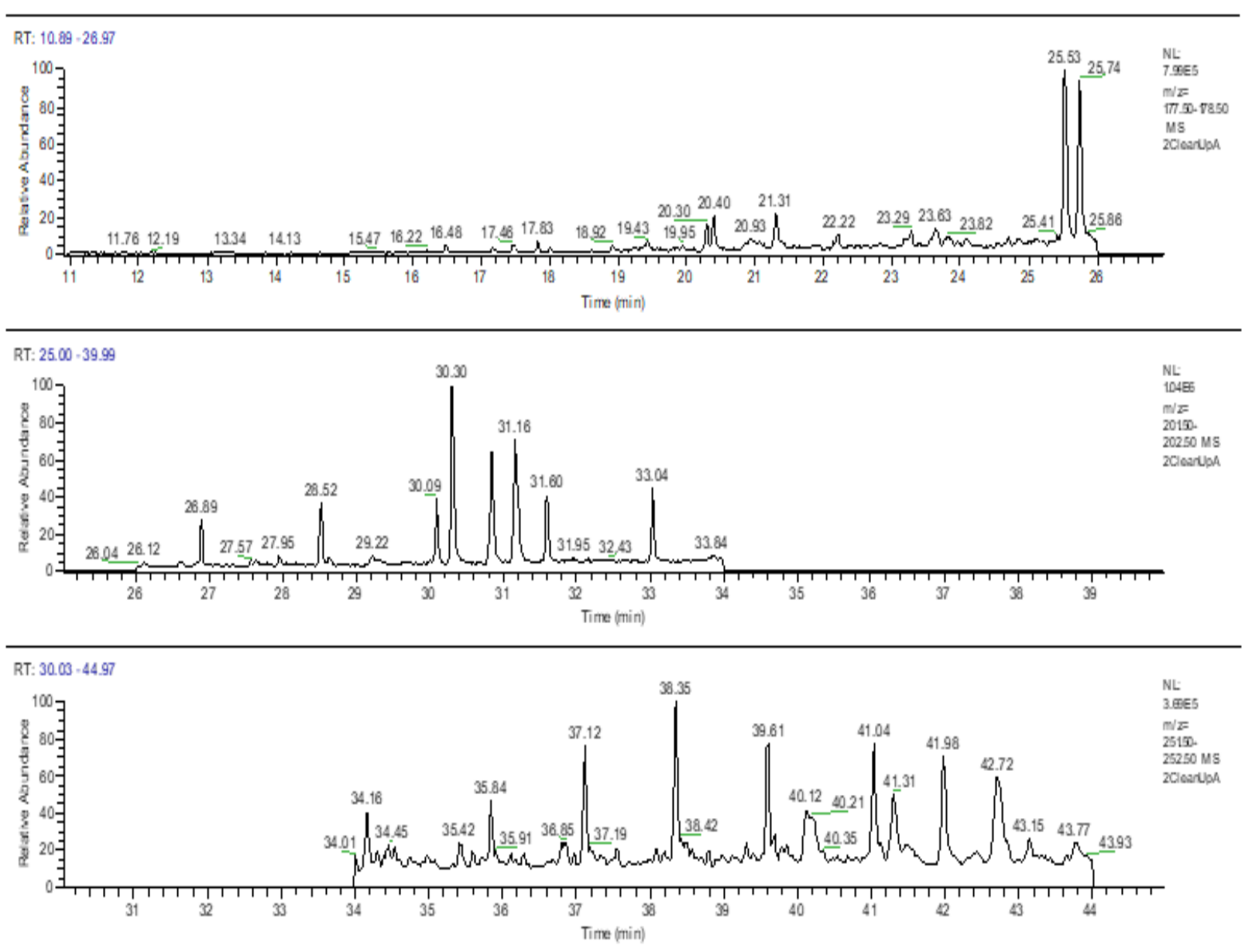

Figura 15 - Espectro de massa do Teste 2 obtido pelo GC-MS. 
TESTE 3

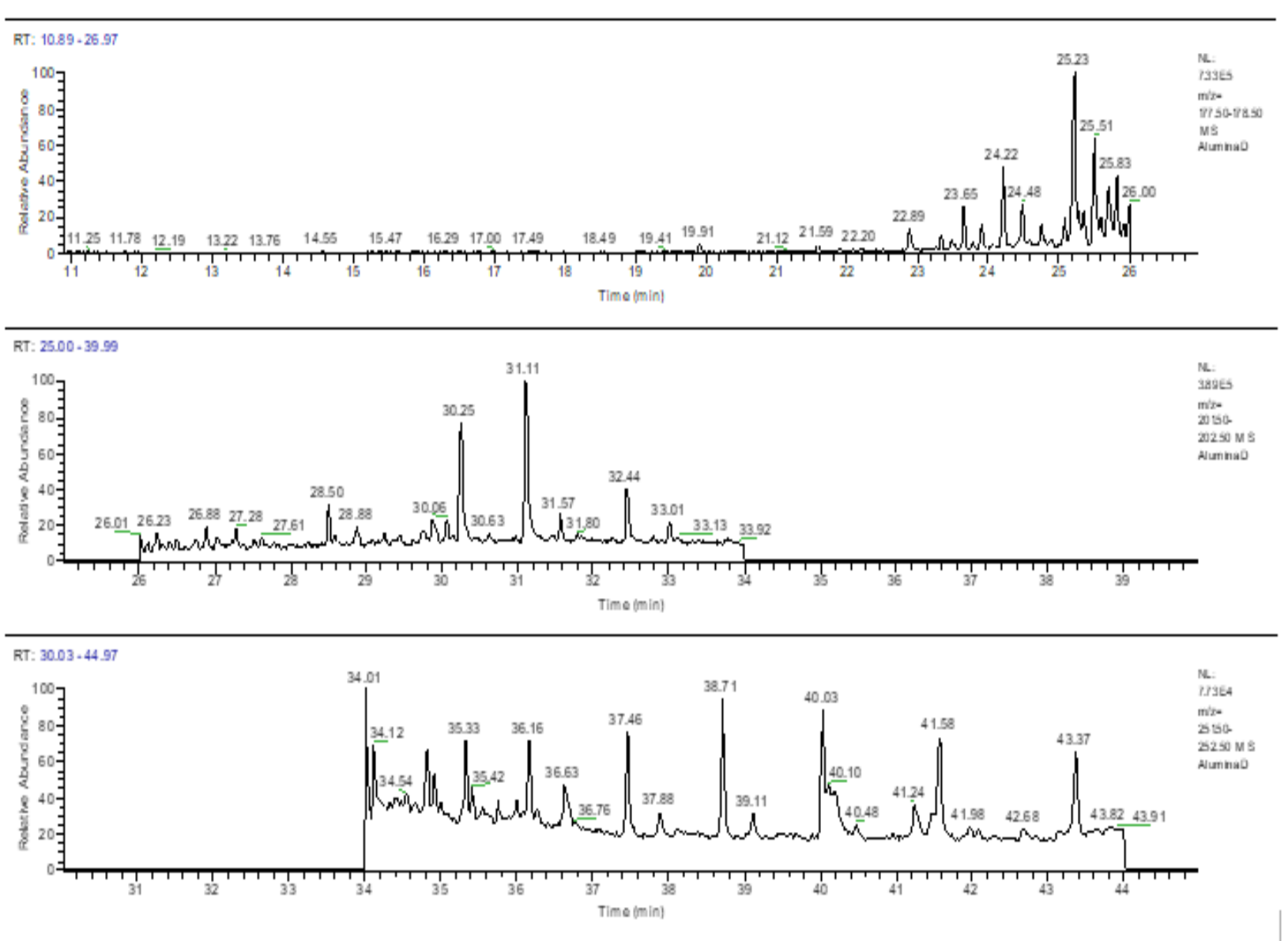

Figura 16 - Espectro de massa do Teste 3 obtido pelo GC-MS. 


\section{TESTE 4}

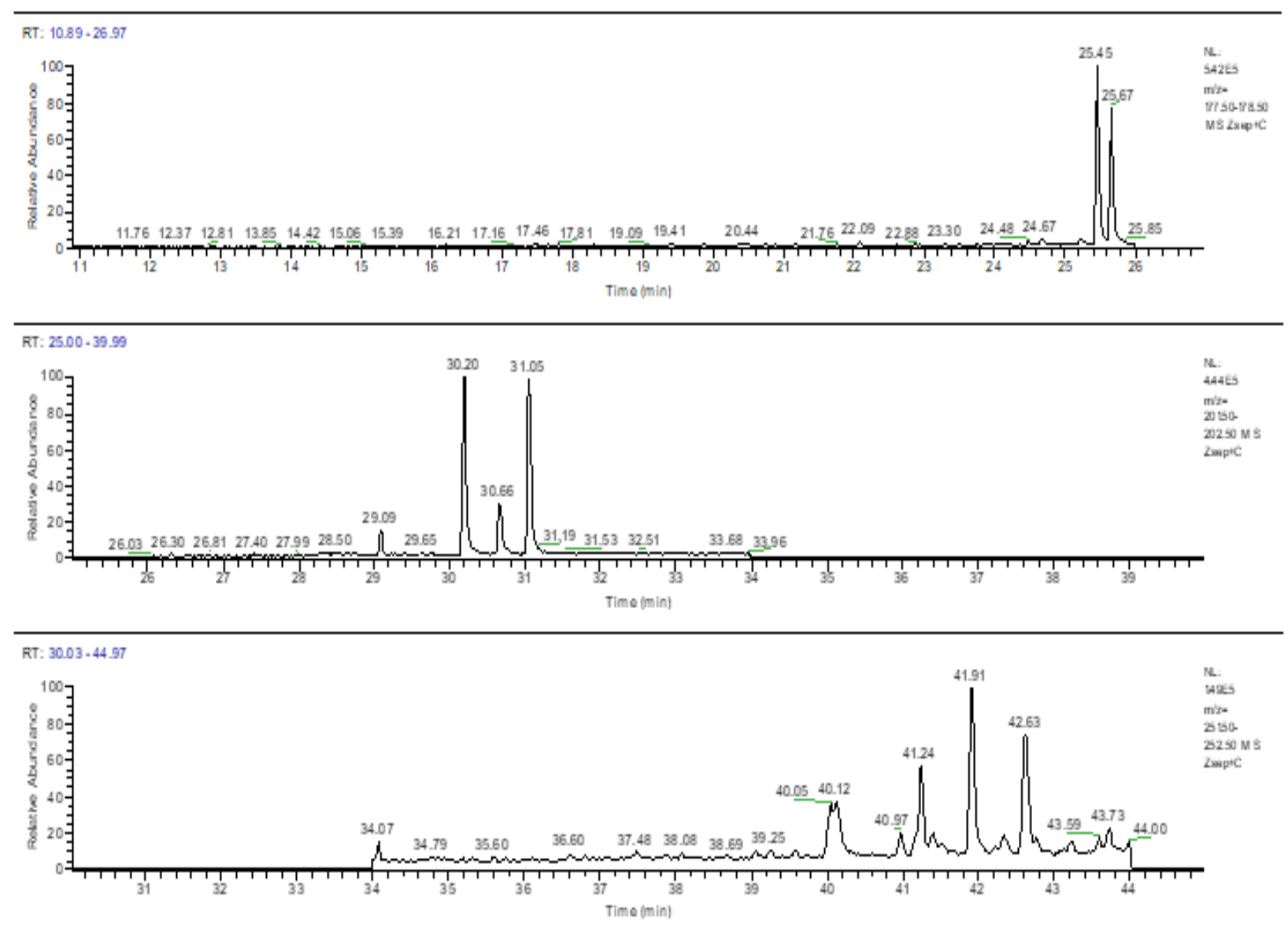

Figura 17 - Espectro de massa do Teste 4 obtido pelo GC-MS. 


\section{TESTE 5}
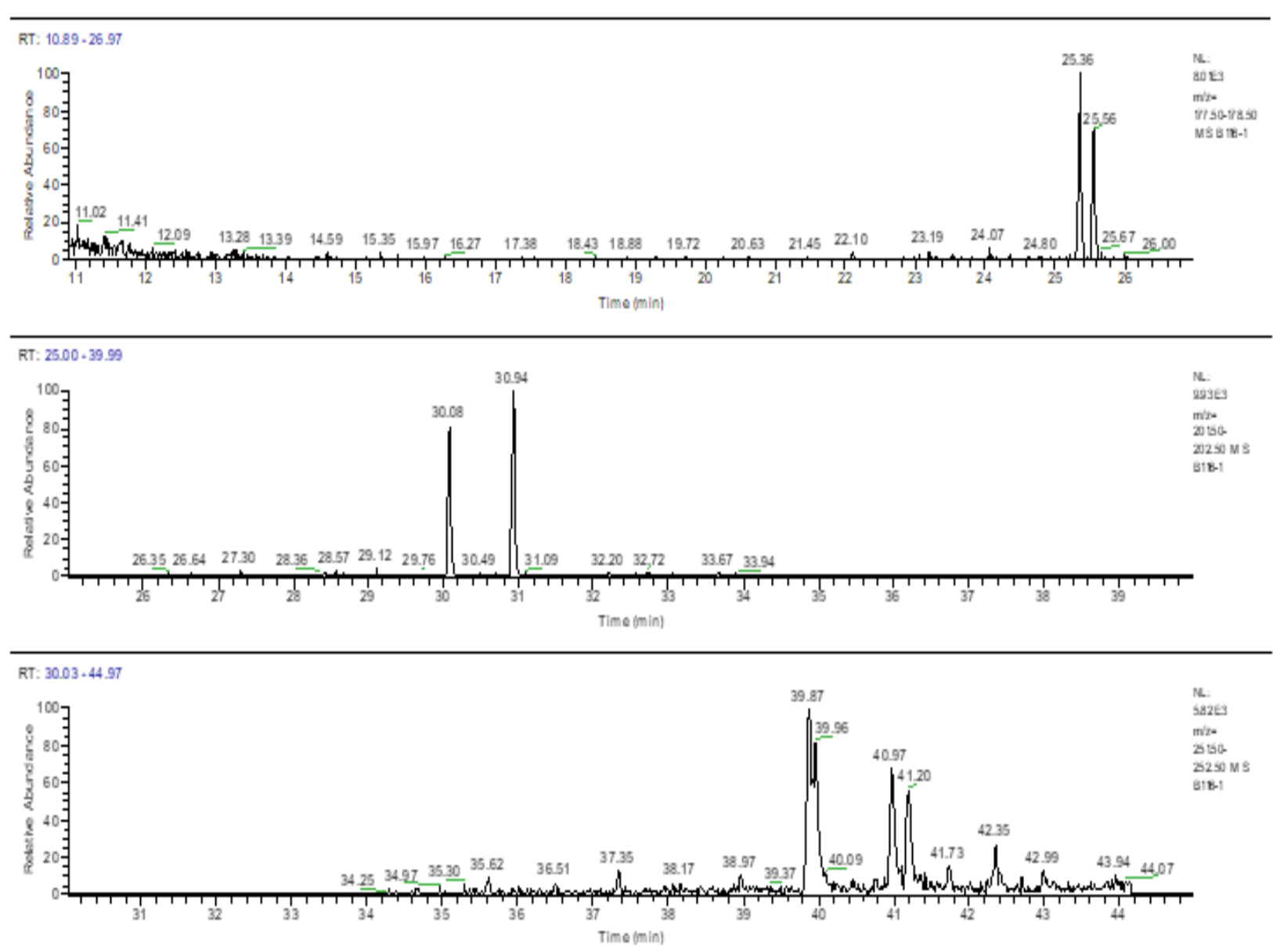

Figura 18 - Espectro de massa do Teste 5 obtido pelo GC-MS.

Analisando os espectros de massa dos testes realizados, conclui-se que o especttro de massa do teste 1 apresentou interferências, prejudicando a análise dos HPAs, assim como os espectros de massa dos testes 2 e 3 que apresentaram ruídos, esses picos são provenientes de um extrato com a presença de contaminantes que interferem na análise. Em relação aos espectros de massa dos testes 4 e 5 , ambos são semelhantes e com pequenas diferenças, sendo o espectro de massa do teste 5 mais ideal, por apresentar uma coluna de sílica e alumina em sua etapa, assegurando que o extrato esteja mais limpo e com ausência de interferentes, implicando em menores danos e manutenções constantes ao GC-MS. 


\section{Conclusões}

O método proposto é simples, rápido de executar, econômico e foi satisfatório para a extração de HPAs em mexilhões, além de realizar várias extrações simultaneamente. Apresentou algumas vantagens, como a quantidade de massa da amostra, da redução do volume de solvente gasto para cada extração, ocasionando na economia do consumo desses reagentes e da massa de adsorventes comparado a métodos convencionais que demandam massa da amostra, volume de solvente e de adsorventes maiores. Esses fatores em conjunto tornam o método menos agressivo ao ambiente, respeitando as ideias da Química Verde.

A avaliação dos parâmetros de validação permitiu concluir que o método apresentou linearidade aceitável segundo os padrões do INMETRO e da ANVISA, além de boa sensibilidade. A seletividade do método foi satisfatória, uma vez que após testes para melhorar a purificação do extrato foi possível identificar os analitos de interesse sem a presença de outras substâncias interferentes. A exatidão do método foi assegurada com o material de referência, tendo como resultado recuperações entre 53,7 e $131 \%$ e a precisão do método entre 0,5 e $33,6 \%$, sendo esse último valor em específico para o criseno.

Os limites de detecção estão entre 0,377 e 7,45 ng g ${ }^{-1}$ e o limite de quantificação entre 1,13 a 22,4 $\mathrm{ng} \mathrm{g}^{-1}$, ficando um pouco altos. Com o cenário atual da pandemia, a realização de mais análises em laboratório foi interrompida, com isso não foi possível obter novos experimentos para melhorar alguns resultados, como por exemplo dos limites de detecção, limites de quantificação e de precisão.

Além disso, durante o trabalho, algumas dificuldades foram encontradas, o método trouxe algumas implicações ao GC-MS, isso se deve ao fato da característica da amostra que possui alto teor lipídico. Esses contaminantes acabaram prejudicando a leitura e quantificação dos analitos e comprometeram o equipamento, sendo necessário manutenções constantes. Para isso, além de otimizar e validar o método, foram realizados testes de otimização da purificação para obter resultados com ausência de contaminantes para não comprometer e gerar danos ao equipamento. 
A purificação do extrato foi melhor no teste 5 , seu espectro de massa não possuía interferentes em comparação aos demais testes, podendo assim analisar os compostos sem que houvesse coeluição entre os analitos de interesse e possíveis interferentes, além de causar menos danos ao equipamento.

Desta forma, o trabalho realizado permitiu validar o método de acordo com os critérios necessários para tal, mas para que o método QuEChERS possa ser utilizado em rotina na avaliação da contaminação de mexilhões por HPAs é necessário melhorar os limites de quantificação para alguns compostos, a fim de alcançar os limites estabelecidos em legislações internacionais para garantir a qualidade desses animais para consumo humano. Uma proposta para resolver essa questão é realizar um experimento utilizando $2,0 \mathrm{~g}$ de amostra, $2 \mathrm{~mL}$ de água, $4 \mathrm{~mL}$ da mistura de solventes (acetona, acetato de etila e isoctano, 2:2:1 v/v) para a etapa de extração. Outro ponto a destacar é que na etapa de purificação, a melhor resposta foi com o uso de $500 \mathrm{mg}$ de Z-sep+ e uma coluna de sílica e alumina. Essa coluna extra de purificação representa uma etapa adicional ao método tradicional do QuEChERS, aumentando o consumo de materiais e tempo de análise, mas é fundamental para garantir a produtividade no uso do GC-MS. A despeito disso, e garantido o ajuste para atingir melhores limites de quantificação, esse método ainda representa uma alternativa vantajosa em relação aos métodos tradicionais. Particularmente, pode ser um método para uso na contaminação de mexilhões após um derrame de petróleo, que requer um número grande de análises químicas em curto período de tempo. 


\section{Referências bibliográficas}

Abdel-Shafy, H. I.; Mansour, M. S. A review on polycyclic aromatic hydrocarbons: source, environmental impact, effect on human health and remediation. Egyptian Journal of Petroleum, vol. 25(1), 2016, pag. 107-123.

Agency for Toxic Substances and Disease Registry, Polycyclic Aromatic Hydrocarbons. ATSDR, 1996.

Anastassiades, M., Scherbaum, E., Tasdelenb., Stajnbaher, D. Recent Developments in QuEChERS Methodology for Pesticide Multiresidue Analysis. Pesticide Chemistry: Crop Protection, Public Health, Environmental Safety. Wiley$\mathrm{VCH}$, Weinheim, Germany, p.439, 2007.

Angioni, A., Porcu, L., Secci, M., \& Addis, P. QuEChERS Method for the Determination of PAH Compounds in Sardinia Sea Urchin (Paracentrotus lividus) Roe, Using Gas Chromatography ITMS-MS Analysis. Food Analytical Methods, vol. 5, 2012, p. 1131-1136.

ANVISA - Agência Nacional de Vigilância Sanitária. Guia para validação de métodos analíticos e bioanalíticos. RE no 899, de 29/05/2003.

Bansal, V.; Kim, K.; Review of PAH contamination in food products and their health hazards. Environment International, 2015, v.84, 26-38.

Bjorklund, E. and Nilsson, T. (2000) Pressurized Liquid Extraction of Persistent Organic Pollutants in Environmental Analysis. Trends in Analytical Chemistry, vol. 19, no.7, pp. 434-445.

Bojes, H. K. and Pope, P.G. (2007) Characterisation of EPA's 16 priority pollutant polycyclic aromatic hydrocarbons (PAHs) in tank bottom solids and associated contaminated soils at oil exploration and production sited in Texas. Regulatory Toxicology and Pharmacology, Vol. 47, pp. 288-295.I

Brito, N M.; Junior, A.O. P; Posele, L.; Ribeiro, M.L. Validação de métodos analíticos: Estrategia e Discurção. Pesticidas: Revista Ecotoxicologia e Meio Ambiente, vol.13, 2013, pag. 129-146.

Caldas, S. S.; Rombaldi, C.; Cerqueira, M. B. R.; Soares, B. M.; Primel, E. G. Avanços recentes da MSPD para extração de resíduos de agrotóxicos, PPCPs, 
compostos inorgânicos e organometálicos. Scientia Chromatographica, 2013, v. 5, n. 3, 190-213.

Camel, V. Recent Extraction Techniques for Solid Matrices-Supercritical Fluid Extraction, Pressurized Fluid Extraction and Microwave-Assisted Extraction: Their Potential Pitfalls. The Analyst, vol. 126, 2001, p.1183-1193.

Capelo, J.L., Maduro, C. and Vilhena, C. Discussion of Parameter Associated With the Ultra Solid Liquid Extraction for Elemental Analysis (Total Content) by Electrothermal Atomic Absorption Spectrometry, An Overview. Ultrasonics Sonochemistry, vol. 12, 2005, p. 225-232.

Capriotti, A. L., Cavaliere, C., Foglia, P., Samperi, R., Stampachiacchiere, S., Ventura, S., \& Laganà, A. Recent advances and developments in matrix solidphase dispersion. TrAC Trends in Analytical Chemistry, vol. 71, 2015, p. 186-193.

Capriotti, A.L., Caruso, G., Cavaliere, C., Foglia, P., Samperi, R. and Lagana, A Multiclass Mycotoxin Analysis in Food, Environmental and Biological Matrices with Chromatography/Mass Spectrometry. Mass Spectrometry Review, vol. 31, 2011, p. 466-503.

Caruso, M. S. F.; Alaburda, J. Hidrocarbonetos policíclicos aromáticos benzo(a)pireno: uma revisão. Revista Instituto Adolfo Lutz, 2008, v. 67, n.1, 1- 27.

Chemat, F.; Rombaut, N.; Sicaire, A. G.; Meullemiestre, A.; Fabiano-Tixer, A. S.; Abert-Vian, M. Ultrasound assisted extraction of food and natural products. Mechanisms, techniques, combinations, protocols and applications. Ultrasonics Sonochemistry, n. 34, p. 540-560, 2017.

Chemo, Beginners Guide to Soxhlet Extraction. Anabolicminds Achive, 2003.

Chen, B.H., Wang, C. Y. and Chiu, C.P. Evaluation of Analysis of Polycyclic Aromatic Hydrocarbon in Meat Products by Liquid Chromatography. Journal of Agricultural Food Chemistry, vol. 44, 1996, p. 2244-2251.

Cordeiro, D.; Lopes, T.G.G.; Oetterer, M.; Porto, E.; Galvão, J.A. Qualidade do mexilhão Perna perna submetido ao processo de cocção, congelamento e armazenamento. Boletim CEPPA, Curitiba, v. 25(1), p. 165- 179, 2007.

Crompton, T.R. Determination of organic substances in water. Editora Wiley, 1984.

Crum, L. A. Comments on the evolving field of sonochemistry by a cavitation physicist. Ultrasonics Sonochemistry, vol. 2, n. 2, p. 147-152, 1995.

Demarco, M. Determinação de hidrocarbonetos policíclicos aromáticos (HPAs) em mexilhão empregando o método QuEChERS e HPLC-FD. Dissertação de mestrado, Instituto de Química, Universidade Federal de Santa Maria, 2017. 
E. Ibanez, A. Cifuentes, Comprehensive Analytical Chemistry. Green Extraction Techniques: Principles, Advances and Applications, Elsevier, 2017.

Eskilsson, C.S. and Bjorklund, E. Analytical-Scale Microwave-Assisted Extraction. Journal of Chromatography A, vol. 902, 2002, p. 227-250.

Farrington, J.W. Bivalves as sentinels of coastal Chemical pollution: The mussel (and Oyster) Watch. Oceanus, v. 26, n. 2, p. 18-29, 1983.

Forsberg, N.D., Wilson, G.R., and Anderson, K. A. Determination of Parent and Substituted Polycyclic Aromatic Hydrocarbons in High-Fat Salmon Using Modified QuEChERS Extraction, Dispersive SPE and GC-MS. Journal of Agricultural and Food Chemistry, vol. 59, 2011, p. 8108 - 8116.

Fontes, K. T. Estudo sobre concentração e tipologia de HPAs em esponja marinha (Hymeniacidon heliophila) e comparação com a acumulação em Perna perna. Dissertação de Mestrado, Pontifícia Universidade Católica do Rio de Janeiro, Departamento de Química, 165f., 2011.

Furlam, E, F.; Galvão, J. A.; Salán, E. O.; Oetterer, M. Composição centesimal e valor calórico de meilhões Perna perna cultivados no litoral norte de São Paulo, Brasil. Bol. Inst. Pesca, São Paulo, v.37(1), p.85-93, 2011.

Gałuszka, A., Migaszewski, Z., \& Namieśnik, J. The 12 principles of green analytical chemistry and the SIGNIFICANCE mnemonic of green analytical practices. TrAC Trends in Analytical Chemistry, vol. 50, 2013, p. 78-84.

H. G. O. Becker et al., ORGANIKUM Química Orgânica Experimental, Fundação CalousteGulbenkian, 2ª Edição, Lisboa, 1997

Hawthorne, S.B., Yang, Y. and Miller, D. J. Comparisons of Soxhlet extraction, pressurized liquid extraction, supercritical fluid extraction and subcritical water extraction for environmental solids: recovery, selectivity and effects on sample matrix. Journal of Chromatography A, vol. 892, 2000, p. 421-433.

Hossain, M. B.; Tiwari, B. K.; Gangopadhyay, N.; O’Donnell, C. P.; Brunton, N. P.; Rai, D. K. Ultrasonic extraction of steroidal alkaloids from potato peel waste. Ultrasonics Sonochemistry, n. 21, p. 1470-1476, 2014.

Instituto Nacional de Metrologia, Normalização e Qualidade Industrial (INMETRO); Orientações sobre Validação de Métodos de Ensaios Químicos, DOQ-CGCRE-008, 2021.

Johnson, Y.S. Detemination of Polycyclic Aromatic Hydrocarbons in Edible Seafood by QuEChERS-Based Extraction and Gas Chromatography-Tandem Mass Spectrometry. Journal of Food Science, vol. 77, no. 7, 2012, p. T131- T137. 
Júnior, A. R. V. Desenvolvimento e validação de método para determinação de hidrocarbonetos policíclicos aromáticos em camarão (Litopenaeus Vannamei). Dissertação de mestrado, Instituto de Química, Universidade Federal de Sergipe,2017.

Junior, D. S., Francisco, J. K., Madson de Godoi, P. and Mauro, K. (2006) Currents on Ultrasound-Assisted Extraction for Sample Preparation and Spectroscopic Analytes Determination. Taylor \& Francis, vol. 41, pp. 305-321.

Kalachova, K., Pulkrabova, J., Drabova, L., Cajka, T., Kocourek, V. and Hajslova, J. (2011) Simplified and Rapid Determination of Polychlorinated Biphenyls Polybrominated Diphenyl Ethers, and Polycyclic Aromatic. Chimica Acta, vol. 707, pp. 84-91.

Lai, J. F., \& Franke, A. A. Analysis of circulating lipid-phase micronutrients in humans by HPLC: Review and overview of new developments. Journal of Chromatography B, vol. 931, 2013, p. 23-41.

Lanças, F. M. Avanços recentes e tendências futuras das técnicas de separação: uma visão pessoal. Scientia Chromatographica, 2008

Lanças, F. M. Validação de métodos cromatográficos de análise. Editora RiMa: São Carlos, 2004.

Lehotay, S. J.; Maštovská, K.; \& Yun, S. J. Evaluation of two fast and easy methods for pesticide residue analysis in fatty food matrixes. Journal of AOAC International, vol. 88(2), 2005, pag. 630-638.

Leite, F. Validação em análise química, 5aㅡ ed.; Editora Átomo: Campinas, 2008.

Letellier, M. and Budzinski, H. (1999) Microwave Assisted Extraction of Organic Compounds. Analusis, vol. 27, pp. 259- 271.

M. Anastassiades, S.J. Lehotay, D. Stajnbaher, F.J. Schenck, Fast and easy multiresidue method employing acetonitrile extraction/partitioning and "dispersive solid-phase extraction" for the determination of pesticide residues in produce, $\mathrm{J}$. AOAC Int. 86 (2003) 412 e 431.

Madureira, T. V., Velhote, S., Santos, C., Cruzeiro, C., Rocha, E., \& Rocha, M. J. A step forward using QuEChERS (Quick, Easy, Cheap, Effective, Rugged, and Safe) based extraction and gas chromatography-tandem mass spectrometrylevels of priority polycyclic aromatic hydrocarbons in wild and commercial mussels. Environmental Science and Pollution Research, vol. 21, 2014, p. 6089-6098.

McDonnell, C.; Tiwari, B. K. Ultrasound: A clean, green extraction technology for bioactives and contaminants. Comprehensive Analytical Chemistry, vol. 76, p. 1-18, 2017. 
Meire, R. O.; Azeredo, A.; Torres, J. P. M. Aspectos toxicológicos de hidrocarbonetos policíclicos aromáticos, Oecologia Australis, v. 11, n. 2, 2007, 188-201.

Morrison, S. A., Sieve, K. K., Ratajczak, R. E., Bringolf, R. B., \& Belden, J. B. Simultaneous extraction and cleanup of high-lipid organs from white sturgeon (Acipenser transmontanus) for multiple legacy and emerging organic contaminants using QuEChERS sample preparation. Talanta, vol. 146, 2016, p. 16-22.

NEFF, J.M. Bioaccumalation in marine organisms: effect of contaminants from oil well produced water. Coastal Resources and Environmental Management Duxbury, Massachusetts USA.2001.

Netto, A. D. P., Moreira, J. C., Dias, A. E. X. O., Arbilla, G., Ferreira, L. F. V., Oliveira, A. S., \& Barek, J. Avaliação da contaminação humana por hidrocarbonetos policíclicos aromáticos (HPAs) e seus derivados nitrados (NHPAs): uma revisão metodológica. Química Nova, vol. 23(6), 2000, p. 765-773.

Oduntan, A. O. O.; Tavengwa, N. T.; Cukrowska, E.; Mhlanga, S. D.; Chimuka, L. QuEChERS Method Development for Bio-monitoring of low molecular weight polycyclic aromatic hydrocarbons in South African carp fish using hplcfluorescence: an initial assessment. South African Journal of Chemistry, v. 69, 2016, p. 98-104.

Omar, N., Bakar, J. and Muhammad, K. (2013) Determination of Organochlorine Pesticides in Shrimps by Gas Chromatography-Mass Spectrometry Using a Modified QuEChERS approach. Food Control, vol. 34, pp. 318-322.

Pare, J.J.R. and Belanger, J.M.R. (1994) Microwave-Assisted Process (MAPTM) a: A New Tool for the Analytical Laboratory. Trends in Analytical Chemistry, vol. 13, no. 4, pp. 176-184.

Pena, M.T. Casais, M.C. Mejuto, M.C. Cela, R. and Phan-tan-Lua, R. (2006) Optimization of a Microwave-assisted Extraction method for the analysis of Polycyclic Aromatic Hydrocarbons from Fish Samples. Journal of Chromatography $A$, vol. 1121, pp. 163-169.

Plaza-Bolaños, P.; Frenich, A. G.; Vidal, J. L. M. Polycyclic aromatic hydrocarbons in food and beverages. Analytical methods and trends. Journal of chromatography A, vol. 1217(41), 2010, pag. 6303-6326.

Płotka-Wasylka, J., Gałuszka, A., \& Namieśnik, J. Green Analytical Chemistry: Summary of Existing Knowledge and Future Trends. Green Analytical Chemistry, 2019, p. 431-449. 
Poster, D.L., Schantz, M.M., Sander, L. C., Wise, S.A. Analysis of polycyclic aromatic hydrocarbons (PAHs) in environmental samples: a critical review of gas chromatographic (GC) methods. Analytical and Bioanalytical Chemistry, vol. 386, p. 859-881, 2006.

Ramalhosa, M. J.; Paíga, P.; Morais, S.; Sousa, A. M.; Gonçalves, M. P.; Delerue-Matos, C.; Oliveira, M. B. P. P. Analysis of polycyclic aromatic hydrocarbons in fish: evaluation of a quick, easy, cheap, effective, rugged, and safe extraction method. Journal of Separation Science, vol. 32, 2009, p. 3529 3538.

Ribani, M.; Bottoli, C. B. G.; Collins, C. H.; Jardim, I. C. S. F.; Melo, L. F. C. Validação em Métodos Cromatográficos e Eletroforéticos. Química Nova, 2004, v. 27 , n. 5, 771-780.

Richter, B.E., Jones, B.A., Ezzell, J.L. and Porter, N.L. (1996) Accelerated Solvent Extraction: A Technique for Sample Preparation. Analytical Chemistry, vol. 68, pp. 1033-1039.

Rejczak, T., \& Tuzimski, T. (2015). A review of recent developments and trends in the QuEChERS sample preparation approach. Open Chemistry, 13(1). doi:10.1515/chem-2015-0109

Santiago, I. U., Molisani, M. M., Nudi, A. H., Scofield, A. L., Wagener, A. de L. R., \& Limaverde Filho, A. M. Hydrocarbons and trace metals in mussels in the Macaé coast: Preliminary assessment for a coastal zone under influence of offshore oil field exploration in southeastern Brazil. Marine Pollution Bulletin, vol. 103, 2016, p. 349-353.

Shirsath, S. R., Sonawane, S. H., \& Gogate, P. R. (2012). Intensification of extraction of natural products using ultrasonic irradiations-A review of current status. Chemical Engineering and Processing: Process Intensification, vol. 53, 2012 p. 10-23.

Silva, C. G. A. Desenvolvimento de fases estacionárias C18 termicamente imobilizadas sobre sílica e sílicas metalizadas e suas caracterizações químicas, físicas e cromatográficas utilizando a cromatografia líquida de alta eficiência (CLAE) e a cromatografia com fluido supercrítico (CFS). Tese (Doutorado em ciências) - Universidade Estadual de Campinas, Instituto de Química, Campinas, 2013.

Sisinno, C. L. S.; Oliveira-Filho, E. C.; Princípios de toxicologia ambiental: Conceitos e aplicações. Editora Interciência: Rio de janeiro, 2013. 
Toma, M.; Vinatoru, M.; Paniwnyk, I.; Mason, T. J. Investigation of the effects of ultrasound on vegetal tissues during solvent extraction. Ultrasonic Sonochemistry, vol. 8; p. 137-142, 2001.

UNITED STATES ENVIROMENTAL PROTECTION AGENCY. USEPA 3550B: Ultrasonic Extraction. Acesso em: 6 de abr. 2021.

Vieira, R. Y. Avaliação regional da contaminação por hidrocarbonetos policíclicos aromáticos (HPAs) na região costeira do sudeste do Brasil usando mexilhões (Perna perna Linneaus 1758) como biomonitores. Dissertação (Mestrado) - Universidade Federal do Rio de Janeiro, Faculdade de Oceanografia , 2012.

Vives, I., Grimalt, J.O. Fernandez, P. and Rosseland, B. (2004) Polycyclic aromatic hydrocarbons in fish from remote and high mountain lakes in Europe lakes in Europe and Greenland. Science of the total environment, vol. 324, pp. 6777.

Wang, L. and Weller, C.L. (2006) Recent Advances in Extraction of Nutraceuticals from Plants. Trends in Food Science and Technology, vol. 17, pp. 300-312.

Zhang, Y.; Dong, S.; Wang, H.; Tao, S.; Kiyama, R. Biological impact of environmental polycyclic aromatic hydrocarbons (ePAHs) as endocrine disruptors. Environmental Pollution Vol. 213, 2016, p. 809-824.

Yoshimine, R. V., \& Carreira, R. S. (2012). PAHs in cultured mussels Perna perna from a Southeastern Brazilian Bay. Journal of the Brazilian Chemical Society, 23(8), 1429-1436. doi:10.1590/s0103-50532012005000003 